Marquette University

e-Publications@Marquette

Master's Theses (2009-)

Dissertations, Theses, and Professional Projects

\title{
Effect Of Occlusal Vertical Dimension On Lip Positions At Smile
}

Jang-Ching Chou

Marquette University

\section{Recommended Citation}

Chou, Jang-Ching, "Effect Of Occlusal Vertical Dimension On Lip Positions At Smile" (2013). Master's Theses (2009 -). Paper 185. http://epublications.marquette.edu/theses_open/185 


\title{
EFFECT OF OCCLUSAL VERTICAL DIMENSION ON LIP POSITIONS AT SMILE
}

\author{
by \\ Jang-Ching Chou, D.D.S.
}

A Thesis submitted to the Faculty of the Graduate School, Marquette University,

In Partial Fulfillment of the Requirements for the Degree of Master of Science

Milwaukee, Wisconsin

May 2013 


\title{
ABSTRACT \\ EFFECT OF OCCLUSAL VERTICAL DIMENSION ON \\ LIP POSITIONS AT SMILE
}

\author{
Jang-Ching Chou, D.D.S.
}

Marquette University, 2013

Purpose: In full mouth reconstructive dentistry, the occlusal vertical dimension(OVD) is often increased to provide adequate restorative space or for esthetic reasons. The purpose of this study was to analyze the effect of occlusal vertical dimension on dimensional measurements of the smile.

Materials and Methods: 30 dental students, 12 male and 18 female between the ages of $21-30$ participated in this study. Polyvinyl Siloxane bite splints of $2 \mathrm{~mm}, 4 \mathrm{~mm}$, $6 \mathrm{~mm}, 8 \mathrm{~mm}$ thicknesses were fabricated on stone casts mounted on semi-adjustable articulators. A wall-mounted head positioning device, modified from a cephalometric unit was used to stabilize head positions. Three photographs each at OVD of $+0 \mathrm{~mm},+2 \mathrm{~mm}$, $+4 \mathrm{~mm},+6 \mathrm{~mm},+8 \mathrm{~mm}$ were taken using a DSLR camera mounted on a tripod. Measurements were made in Adobe Photoshop CS5, using the width of the maxillary central incisors to convert pixel measurements to millimeter measurements.

Results: One way repeated measures ANOVA found statistically significant differences in interlabial gap height, incisal edge - lower lip length, and display zone area with increasing OVD. No statistically significant differences were found for intercommisural width and incisal edge - upper lip length.

Conclusions: This study demonstrates that excessive increase of OVD may lead to excessive interlabial gap height, incisal edge - lower lip length, and display zone area. A lengthening of the upper lip at smile should not be expected with increasing OVD. In addition, a change in the width of the smile should not be expected with increasing OVD. 


\title{
ACKNOWLEDGEMENTS
}

\author{
Jang-Ching Chou, D.D.S.
}

I would like to thank my wife, Dr. Shu-Ling Lu for her love and support throughout my residency.

I would like express my deepest gratitude to Dr. Geoffrey Thompson, my thesis director and director of the Graduate Prosthodontics program for his enormous support for this project.

I would also like to extend my appreciation to my committee members: Dr. Harshit Aggarwal, Dr. Jose Bosio, Dr. Daniel Domagala, Dr. Gerald Ziebert for their help and advice.

I would like to thank Mr. Jon Irelan, Dr. Carolyn Strash, Mr. Masaaki Izumi, fellow residents, and supporting staff for their help.

I would like to thank Dr. Arthur Hefti, Dr. Jessica Pruszynski, and Mr. Lih-Ching Chou for their help with data analysis.

Special thanks to the American Academy of Fixed Prosthodontics Tylman Research Fund for funding the project, without which this project would not have been possible. And to my mother and father, for all of their support. 


\section{TABLE OF CONTENTS}

ACKNOWLEDGEMENTS. .. $\mathrm{i}$

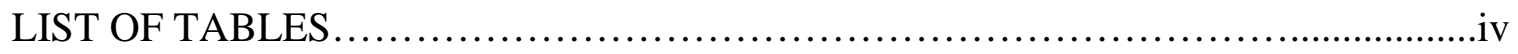

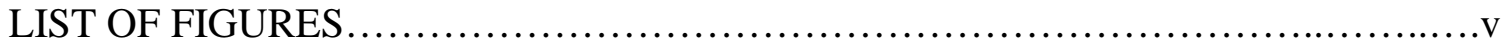

\section{CHAPTERS}

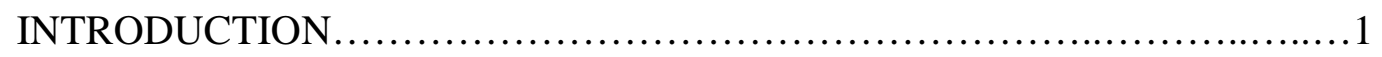

LITERATURE REVIEW ............................................

I. Methods for Analysis of Soft Tissue Profile...........................

II. Attractiveness of the Smile.......................................5

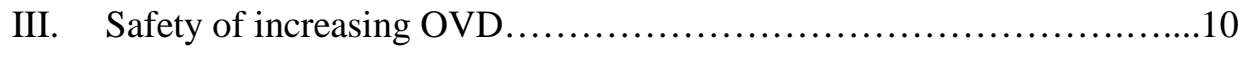

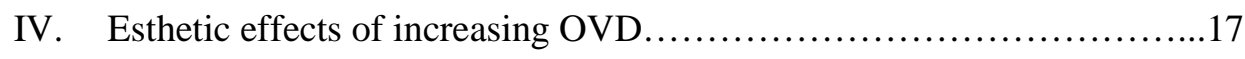

V. Determination of Incisal Edge Position..........................20

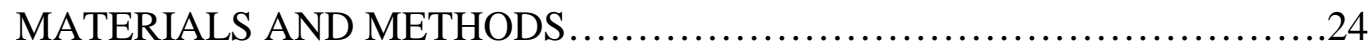

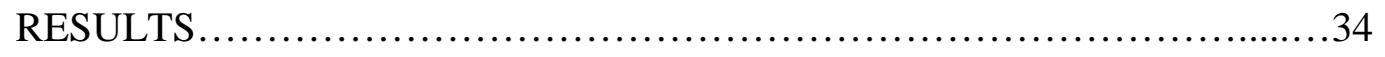

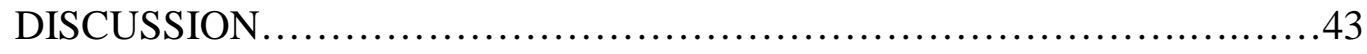

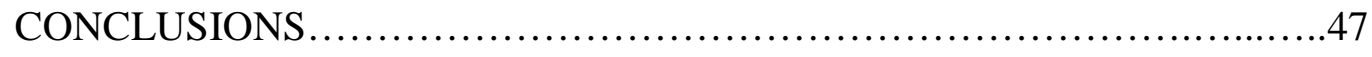

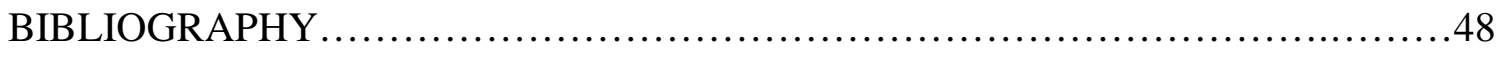




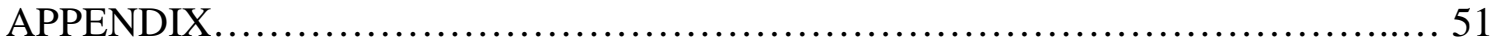




\section{LIST OF TABLES}

Table 1. Inclusion and exclusion criteria........................................

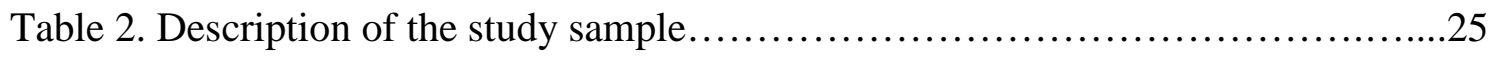

Table 3. Results for smile measurements..................................... 36

Table 4. Results of one-way repeated measures ANOVA ….........................37 


\section{LIST OF FIGURES}

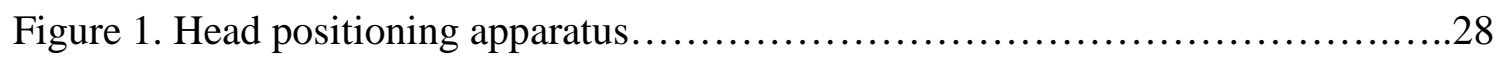

Figure 2. Representative photograph of the smile (at +2mm OVD) ....................30

Figure 3. Points of measurement..................................................

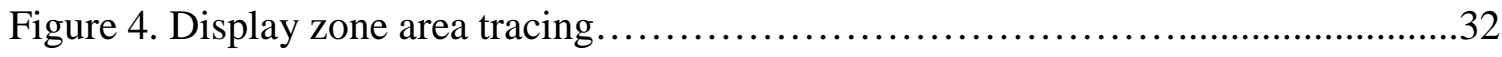

Figure 5. Individualized data for interlabial gap height..............................38

Figure 6. Individualized data for intercommisural width..............................39

Figure 7. Individualized data for incisal edge - upper lip..........................40

Figure 8. Individualized data for incisal edge - lower lip...........................41

Figure 9. Individualized data for display zone area...............................42 


\section{CHAPTER I}

\section{INTRODUCTION}

The restorative needs for the prosthodontic patient frequently require an increase in occlusal vertical dimension (OVD). ${ }^{1}$ This may be due to loss of tooth structure and concomitant loss of OVD, supereruption of opposing teeth into edentulous spaces, or for esthetic reasons. ${ }^{2}$ It is often difficult to assess whether OVD has truly been lost. ${ }^{3}$ Therefore, it may be prudent to focus on whether alteration in OVD is restoratively acceptable. $^{1}$

Another consideration for the alteration in OVD is changes in soft tissue profile. In addition to the correct proportions of the teeth, the relationship of the teeth to the lips and gingiva is also an important factor for an esthetic smile. During a normal smile, the upper lip should rest at the level of the mid-facial gingival margins of the maxillary anterior teeth. ${ }^{4}$ Furthermore, the gingival outline of the maxillary anterior teeth should follow the upper lip line. ${ }^{5}$ The incisal edges of the maxillary anterior teeth should follow the curvature of the lower lip. ${ }^{6}$

As the vertical dimension of occlusion increases, the distance between the maxilla and the mandible is increased. Therefore, it is likely that the position of the upper and lower lips at smile will also change. The movement of the corners of the mouth is dictated by the modiolus, where eight muscles meet. In particular, the zygomaticus major and the triangularis muscles, which insert into the zygomatic arch and the mandible, respectively. Thus, by changing the OVD, it is possible that the distance between the corners of the mouth will be altered. 
Treatment planning for optimal esthetics has been one of the main focuses of the prosthodontics community. Numerous publications have discussed concepts of treatment planning to optimize occlusion, function, and esthetics. ${ }^{2,7-11}$ However, there remains a lack of scientific data, especially in the esthetic implications of changing the occlusal vertical dimension. The purpose of this study was to analyze the effect of occlusal vertical dimension on dimensional measurements of the smile. 


\section{CHAPTER II}

\section{LITERATURE REVIEW}

\section{Methods for Analysis of Soft Tissue Profile}

\section{Direct Analysis}

Vig and Brundo ${ }^{11}$ used a millimeter ruler to perform measurements between the teeth and the lips. Other authors have also used the ruler to perform measurements. Misch $^{12}$ stated that the handheld ruler as a measurement device may be flawed because the examiner may distort the lip/tooth relationship. Inter-examiner differences may also hinder accurate measurement of lip and tooth positions. ${ }^{12}$

\section{Photographic Analysis}

Gross et al ${ }^{13}$ utilized facial markers adhered to the subjects' faces for measurement. Photographs were taken and printed out at a 1:1 ratio, and measurements were made between the facial markers.

$\mathrm{Hu}^{14}$ evaluated esthetic parameters during enjoyment smiling using digital photography. A ruler fixed on a tripod was placed near the subject's face as a reference to enable calibration. The clinical crown lengths of the maxillary central incisors were measured to guarantee the reliability of the photographic measurements. Images were measured in Adobe Photoshop CS4 software.

\section{Video Analysis}


Using video analysis, Ackerman ${ }^{15}$ evaluated smiles of 50 young patients (27 boys, 23 girls) with a mean age of 12.5 years. 1242 video recordings were obtained. The video recordings were imported into iMovie software. The frame representing the subject saying "chee" from the word "cheese", and another frame representing the posed social smile were obtained. These images were imported into SmileMesh computer software, which overlays a grid onto the images to permit measurements. The interlabial gap at posed smile was found to be $8.41 \pm 2.10 \mathrm{~mm}$, and the maximum incisor exposure was $6.36 \pm 1.67 \mathrm{~mm}$. It was found that during a posed smile, greater maximum incisor exposure, smile width, smile index (intercommisure width divided by interlabial gap), and percent tooth below intercommisure measurements were found compared to speech ("chee"). He concluded that, "video analysis provides an accurate recording of the patient's speech, the posed social smile, and the Duchenne (enjoyment) smile". Desai ${ }^{16}$ utilized two plastic rulers glued together at a 90 degree angle as a measurement device. Subjects held this measurement device against the chin during video recording. Chetan ${ }^{17}$ used a horizontally placed ruler under the chin as a measurement device.

Van der Geld ${ }^{18}$ recorded videographic measurements during spontaneous smile of joy and during speech. Similarly, $\mathrm{Hu}^{14}$ also recorded photographic images at spontaneous smile of joy.

\section{D non-contact imaging}

Non-contact imaging involves a laser or optical sensor capturing 3D images of the face. Schimmel ${ }^{19}$ found minor errors of $0.227 \mathrm{~mm}$ in bench experiments with an optical 
3-dimensional system. Ushijima ${ }^{20}$ found highly reproducible facial landmarks: labrale superior, stomion, labrale inferior, right/left oral fissure points at errors of $<0.4 \mathrm{~mm}$.

\section{Attractiveness of the smile}

Tjan ${ }^{10}$ evaluated smiles of dental students and dental hygiene students between the ages of 20-30 years using 454 full-face photographs. For smile type, $10.57 \%$ were classified as high smile (revealing the total cervico-incisal length of maxillary anterior teeth and a continuous band of gingiva); $68.94 \%$ were classified as average smile (revealing $75-100 \%$ of the teeth); $20.48 \%$ were classified as low smile.

For incisal curve, $84.8 \%$ were classified as parallel (with the lower lip); $13.88 \%$ were classified as straight; $1.32 \%$ were classified as a reverse smile line. For the relationship of the maxillary incisors with the lower lip, $46.61 \%$ touched the lower lip; $34.62 \%$ did not touch the lower lip; $15.76 \%$ had the incisal portions covered by the lower lip.

In a different study, $\mathrm{Hu}^{14}$ analyzed soft tissue display during enjoyment smiling in 66 Caucasian subjects with a mean age of 28.5 years. Digital photographs were taken with the subjects holding their heads naturally forward. To obtain enjoyment smiles, the patients were induced to laugh. Frequencies of gingival display in the central incisor region for women and men were $42 \%$ and $28 \%$, respectively. The mean gingival display was $1.3 \mathrm{~mm}$ (range 0.0 to $6.4 \mathrm{~mm}$ ). Although women were found to show slightly more gingiva than men, differences were not significant in anterior teeth, premolars, or first molars. Frequencies of papilla display in the central incisor region for women and men were $94 \%$ and $93 \%$ respectively. 
A study by Hochman, Chu, and Tarnow ${ }^{21}$ evaluated papilla display at smile in 420 subjects and categorized gingival display into two basic categories:

1. gingival smile line, which was further divided into 3 categories: high and low gingival smile line (HGSL, LGSL), and "cupid's bow smile line" (CB-GSL) in which the midfacial gingiva of the central incisors was not shown, but gingival tissues of the lateral incisors and/or those distal were shown upon smiling

2. interdental smile line, which was further divided into 3 categories: high, low, and “cupid's bow smile line” (HISL, LISL, CB-ISL)

HGSL was found in $76 \%$ of females, compared to $24 \%$ for males. Comparing age differences, close to $90 \%$ of subjects were categorized as high interdental smile line until the age 80 . Furthermore, $87 \%$ of subjects with a low gingival smile line (LGSL)

exhibited a high interdental smile line (HISL). The author indicated that a misconception existed and that the treatment of the LGSL patient represented a lesser esthetic challenge. They concluded that recognizing the interdental smile line (ISL) in classification is would be important for treatment planning.

Recently, Crawford ${ }^{22}$ evaluated the influence of posterior maxillary gingival margin position. A group of 120 volunteers aged 12 to 80 years were divided into 4 groups of 30 subjects: G1- Hypodontia patients; G2- Periodontitis patients; G3- Patients without either condition; G4- Dentists. The 4 groups of participants were asked to assess six computer-generated photographs of smiles with differences in posterior teeth gingival positions. They found that a strong preference of dentists for posterior gingival margins to be $1 \mathrm{~mm}$ lower than the canine margin. The patient groups (G1, G2, G3) did not have 
as strong a preference, but accepted a zone of posterior configurations from $0 \mathrm{~mm}$ to $2 \mathrm{~mm}$ as esthetically pleasing.

Kattadiyil $^{23}$ evaluated the esthetic preferences of dentists and laypersons of the same smiles taken at 3 different angles (10 degrees above Frankfort Horizontal; 0 degrees from Frankfort Horizontal; 10 degrees below Frankfort Horizontal). Photographs were taken for 100 participants, and 73 evaluators assessed the photographs for esthetics. Most participants judged the top view to be the most pleasing, followed by the center view. The bottom view was judged to be least pleasing for the majority of evaluators.

In the orthodontic literature, McNamara et $\mathrm{al}^{9}$ studied esthetics of the posed smile in growing patients using video analysis. Sixty growing patients with a mean age of 12 years (33 girls, 27 boys) were asked to say "Chelsea eats cheesecake on the Chesapeake," and then smile. The video clips were edited to obtain the frame that "best represented the patient's natural unstrained social smile". SmileMesh software was used for analysis. Attractiveness of the each smile was evaluated using VAS by 30 orthodontists and 30 laypersons. The average interlabial gap was $10.4 \pm 3.7 \mathrm{~mm}$; the average intercommisure width was $61.1 \pm 5.4 \mathrm{~mm}$. No significant correlations were found between gingival display, incisal display, or buccal corridor size and the esthetics of the smile.

Surprisingly, the vertical lip thickness was the most important factor in the esthetics of the smile. They concluded that "fuller lips were associated with with better smiles".

Van der Geld et al ${ }^{18}$ studied age-related differences at rest and smile positions in122 male subjects. The participants were divided into 3 age groups: G1: 20-25; G2: 3540; G3: 50-55. Digital video recordings were made at spontaneous smile of joy, during speech, at rest, and of the full dentition (using lip retractors). The lengths of the teeth 
were measured on the full dentition record, and the display of teeth and gingiva were measured on the spontaneous smiling and speech records. During spontaneous smiling, $75 \%$ of subjects showed teeth up to the maxillary first molar. The lip line heights gradually decreased with age for all maxillary teeth in both speech and spontaneous smiling. In the upper central incisor region, lip line heights during spontaneous smiling decreased by $2 \mathrm{~mm}$ with increasing age from $\mathrm{G} 1$ to $\mathrm{G} 3$. The rest position of the upper lip to the maxillary central incisor also decreased from $5.5 \mathrm{~mm}$ to $2.0 \mathrm{~mm}$.

Desai et a ${ }^{16}$ also evaluated changes in the smile with respect to age. Two hundred twenty one subjects were divided into 5 age groups: $15-19 ; 20-29 ; 30-39 ; 40-49 ; 50+$. Video clips of the subjects smiling were imported into a video editing program, and frames at rest and at the widest commissure-to-commisure posed smile were used for analysis. The mean interlabial gap height at smile for the age group 15-19, 20-29, 30-39, 40-49 were $12 \mathrm{~mm}, 10.42 \mathrm{~mm}, 10.7 \mathrm{~mm}, 8.5 \mathrm{~mm}$, and $9.01 \mathrm{~mm}$ respectively. Incisal edge display and intercommisural width at smile were also found to decrease with increasing age. A decrease of 1.5 to $2 \mathrm{~mm}$ was found for maxillary incisor display at smile with increasing age. The authors stated that these age related changes occurred due to muscle atrophy and decreasing muscle activity and function.

Another study by Chetan ${ }^{17}$ studied age and gender differences in measurements of the smile using video analysis. The 241 subjects were assigned into 4 groups by age: G1: 15-20; G2:21-30; G3:31-40; G4: 41-50). It was reported that with increasing age from G2 - G4, the thickness of the upper lip (labrale superius - stomion superius) decreased. With increasing age from 20 to 50 years, the intercommisural width at rest increased by $3.68 \mathrm{~mm}$ in males, and $2.88 \mathrm{~mm}$ in females. Another interesting finding was that with 
increasing age, the change in upper lip length from rest to smile decreased by $5.58 \%$ in males and by only $1.31 \%$ in females. In both males and females, the change in intercommisural width from rest to smile also decreased with age. This was attributed to the combination of increasing intercommisure widths at rest and decreasing intercommisure widths at smile. For example, in males, the resting intercommisure width increased by $1.2 \mathrm{~mm}$, but the smiling intercommisure width decreased by $3.52 \mathrm{~mm}$. The same was found in females to an even larger degree $(2.44 \mathrm{~mm}$ and $2.72 \mathrm{~mm}$, respectively). Furthermore, there was a decrease in intercommisural height from rest to smile with increasing age. In this respect, the decrease in males was higher $(11.36 \%)$ than in females $(6.23 \%)$. The author attributed these age differences to decreasing tonus and elasticity of the facial muscles with age.

Bidra $^{24,25}$ proposed a classification system of patients for fixed implantsupported prosthesis in the edentulous maxilla. The clinical considerations were based on: maxillary incisal edge position, maxillary cervical edge position and esthetic tooth proportions, smile line, gingival display, and maxillary lip support. The patients were classified into 4 groups: 1) Class I patients require artificial gingiva to obtain prosthesis contour as well as lip contour. 2) Class II patients require gingival-colored prosthetic material only without lip support. 3) Class III patients do not require gingival-colored prosthetic material. 4) Class IV patients have excessive gingiva and may or may not require gingival-colored prosthetic material, depending on choice of intervention. In a follow-up article, Bidra $^{26}$ presented an article on maxillary complete arch fixed implant prosthesis treatment options for patients with excessive gingival display (Bidra Class IV). Management options presented are as follows: 
1) Osteotomy procedures: The osteotomy procedure is undertaken before implant placement so that the bony platform is above the upper smile line. In this respect, the patient is effectively converted from a Class IV patient to a Class II or Class III patient. 2) Lefort I osteotomy: This procedure involves vertical impaction of the maxilla. The Lefort I procedure is recommended for VME patients because the nasal floor and/or maxillary sinuses are elevated to obtain sufficient bone for implant placement.

3) Preprosthetic orthodontic intrusion: This option may also alleviate problems of implants encroaching on the nasal floor

4) Plastic surgery procedures: Lip repositioning procedures, lip lengthening procedures, or Botox injections may be used to correct a short lip or a hypermobile lip. 5) No intervention and conversion to a Class III patient: This option should be used with caution, since papilla-like tissue between adjacent implants is difficult to obtain. Patients should be cautioned that esthetic compromises are necessary.

6) No intervention/reconsider removable prosthetic options: A conventional complete denture, a fixed-detachable overdenture may be utilized, but the patient will need to be warned that future conversion to a fixed restoration would necessitate removal of the existing implants, osteotomy procedures, and placement of implants at a more apical position.

\section{Safety of increasing Occlusal Vertical Dimension}

There has been much debate in the dental literature concerning whether or not it is permissible to increase the occlusal vertical dimension in prosthetic reconstruction. 
Dawson $^{7}$ stated that "Changes in true VDO are not permanent. The VDO will return to its original dimension measurable at the masseter muscle." He advocates that reasons for increasing VDO are not valid, and that it is almost always contraindicated to increase VDO in reconstructions. In cases of assumed "lost" VDO, the process of supereruption of teeth maintains VDO in spite of tooth wear. Even in cases of rapid tooth wear, such as in a tobacco chewer, the author maintains that the attrition of the teeth is maintained by supereruption. The author advises that in certain cases, it is permissible to increase the VDO, such as in cases where increasing the VDO would allow the clinician to reconstruct the occlusion without performing multiple root canal treatments. However, in such cases, multiple postoperative occlusal adjustments would be required, and the VDO will eventually revert back to its original length.

Atwood $^{27}$ conducted a cephalometric study on repeatability of the clinical rest position before and after edentulation in 42 patients. All 42 patients had teeth in occlusion which needed to be extracted. He measured the distance from nasion to gnathion to assess the vertical dimension at rest. Rest positions in the same sitting and at multiple sittings were assessed. The authors found that of the 42 patients studied, 11 showed an increase in the rest vertical dimension, 9 showed a fluctuation around the baseline measurements, and 22 showed a decrease in the rest vertical dimension. Results for variations within single sittings found that 38 subjects had variations between $0-2 \mathrm{~mm}$; 1 subject had a variation of $2.0 \mathrm{~mm}$; 2 subjects had variations between $3-4 \mathrm{~mm}$; and 1 subject had a variation of $4.0 \mathrm{~mm}$. 
Dawson $^{7}$ referenced this article noting the possible single-sitting variation of $4.0 \mathrm{~mm}$ as a reason that occlusal vertical dimension at rest was not a reliable method of assessing the occlusal vertical dimension.

Prombonas $^{28}$ studied the effect of altering the occlusal vertical dimension on biting force in 13 edentulous subjects. The biting force was measured using a gnathodynamometer mounted on base plates. The biting force was measured at three occlusal vertical dimensions: 1) VD<VDO (reduced vertical dimension of occlusion, mean value -8mm) 2) VD=VDO 3) VD>VDO (increased vertical dimension of occlusion, mean value $+15 \mathrm{~mm}$ ). It was found that position 3 (VD>VDO) had the greatest mean biting force value, followed by position 2 (VD=VDO), followed by position 1 (VD<VDO). The authors concluded that the position of maximum bite force is at the maximum opening, and that the "power position" proposed by Boos cannot be used to register the vertical dimension of occlusion.

On the other hand, the majority of recent publications have refuted the notion that VDO cannot be changed.

Spear $^{1}$ described Occlusal Vertical Dimension (OVD) as “.... a highly adaptable position, and there is no single correct vertical dimension". Spear advocated that the OVD which "satisfies the patient's esthetic goals and the clinician's functional goals" be chosen. A 5 step approach was described:

1) Mount the patient's models at a seated condyle position

2) Establish the ideal maxillary incisal edge position, using tooth display at rest and at smile

3) Determine the lingual contour alteration of the maxillary incisors, if necessary 
4) Close the articulator to evaluate the occlusion. In some cases, significant alterations to posterior occlusion is necessary to arrive at the proposed anterior tooth positions, therefore posterior buildups and subsequent opening of the vertical dimension may be needed.

5) An optional step is modification of the mandibular incisors, shortening or lengthening them to arrive at the desired posterior occlusion

The author also notes that in the majority of patients requiring full mouth reconstructions, the condyles will become more seated towards the end of the treatment. This seating of the condyle will enable the length of the masseter muscle to remain the same with a slight increase in occlusal vertical dimension. The author also notes that even if the occlusal vertical dimension does revert back to its original length, it is usually a benign process that neither the patient nor the clinician will notice.

Abduo $^{29}$ performed a systematic review on the safety of increasing vertical dimension of occlusion. He categorized prosthetic concepts for increasing the VDO into removable and fixed concepts. For each category, the increase in VDO can be further divided into full or partial arch coverage concepts. Citing Christensen ${ }^{30}$ and Carlsson ${ }^{31}$, the author concluded that removable concepts for increasing the VDO, especially in partial coverage of the posterior teeth, were more problematic than fixed concepts. In cases where VDO increase was indicated, it may not be beneficial for the patient to wear a removable splint prior to fixed reconstruction. Although partial coverage concepts of increasing the VDO led to dentoalveolar alterations (supereruption or intrusion), full coverage concepts are relatively stable, and do not lead to dentoalveolar alterations. The author concluded that permanent increase of the VDO is a safe and predictable procedure. 
Keough $^{2}$ suggested 4 reasons for increasing the occlusal vertical dimension:

1) To increase interarch space for restorative space

2) To minimize need for crown lengthening or endodontic therapy

3) To change the overbite-overjet relationship of anterior teeth. This is especially advantageous for patients with a severely worn dentition who may present with excessively steep overbite. However, the author also notes that increasing the VDO may increase the overbite of the anterior teeth, causing difficulties in establishing an even contact in centric relation.

4) To create an esthetic change. The author notes that increasing the VDO may allow the clinician to re-establish midface height. The author warns that increasing the VDO for esthetics must also be functionally acceptable.

Carlsson $^{31}$ evaluated the effect of increasing vertical dimension using electromyography (EMG) recording and cephalometry. Six healthy subjects, 2 women and 4 men aged 23 to 46 years participated in this study. Clear acrylic resin splints were constructed to increase the occlusal vertical dimension about $4 \mathrm{~mm}$ in the incisor region. The splints covered mandibular canines, premolars, and molars. Bilateral balanced occlusion was established for each subject and the splints were cemented using temporary cement. Clinical observations took place over a 7 day period. Cephalometric radiographs were taken before and after the bite-raising period. EMG recordings were also conducted. The authors reported symptoms reported by the subjects during the bite-raising period, which included: headache, tenderness in muscle joints, tenderness in muscles, tenderness in teeth, clenching of teeth, cheek biting, problems with chewing, and problems with phonetics. Most of these symptoms were reported to have diminished in severity after the 
first 2 days. In 1 out of the 6 subjects, the clenching of teeth remained after the 7 day observation period. EMG recordings at the postural position in the anterior temporal muscle, posterior temporal muscle, and masseter muscles diminished following splint insertion and after 7 days of use, although statistically significant differences were not found. However, the mean maximal bite force in all three muscles had increased following 7 days of bite-raising. The author concluded that increasing the vertical dimension of occlusion created a new postural position of the mandible, and that "a moderate increase in the vertical dimension of occlusion does not seem to be a hazardous procedure".

Few studies in the literature have looked at OVD increase in fixed restorations over extended periods.

Gross and Ormianer ${ }^{32}$ evaluated the effect of OVD increase on mandibular postural rest position. Using a custom electro-optic chin position measurement device, mandibular postural relations were recorded before and after OVD increase. Full-arch acrylic resin fixed restorations were used to increase the OVD. Measurements were made in relaxed resting posture (RRP) and clinical rest position (CRP) in 8 subjects who required full arch fixed restorations with increased OVD of 3.5 to $4.5 \mathrm{~mm}$. Measurements were made weekly for 1 month. Clinicial signs and symptoms were recorded for each subject. All subjects reported discomfort in the mandibular musculature and speech difficulties at the 1st week after OVD increase. In 7 out of 8 patients, the symptoms subsided after 1 week, and in the remaining patient after 2 weeks, after smoothing lateral excursive inclines (but not reducing the OVD). Repeated measures ANOVA found significant differences between CRP and RRP both before and after OVD increase. CRP 
and RRP recordings for the individual subjects were fluctuant between recordings. The author described the CRP and RRP as, "not rigid points in space, but repeatable resting ranges". The author further concluded that "both CRP and RRP were re-established at increased vertical dimensions of rest".

Following this previous study, Ormianer and Gross ${ }^{33}$ conducted a 2 year followup of mandibular posture following OVD increase in 8 subjects (G1). CRP, RRP, and masseteric EMG values were measured. A control group of dental students who had not undergone OVD increase was included for comparison (G2). In G1, subjects have already developed a new CRP and RRP position, which were different, and remained significantly different for 1 year. At 2 years, 5 out of 8 subjects had statistically significant differences between CRP and RRP. Similar to the previous study, the authors found CRP and RRP ranges to be fluctuant in both G1 and G2. The author described these ranges as being "postural ranges" rather than specific points in space. The author further concluded that the resting face height remained stable over 1 and 2 years after increase in OVD.

Ormianer and Patty ${ }^{34}$ observed complications associated with increased OVD in tooth-borne and implant-borne restorations. 30 patients were divided into 3 groups: Group A: Tooth - Tooth; Group B: Implant - Tooth; Group C: Implant - Implant. Group B patients received $8-11$ implants to support 12-unit FPDs. On average, patients were followed for 66 months. Group C patients received $14-19$ implants in both arches. All 30 patients adapted to the new VDO without TMD signs/symptoms or phonetic problems. Group A patients experienced the highest amount of bone loss (avg 2.3mm), with 12 teeth extracted from caries, periodontitis, or tooth fracture. In Group B, the mean 
bone loss was $2 \mathrm{~mm}$, mostly occurring around posterior teeth than around implants. Group $\mathrm{C}$ patients experienced a mean bone loss of $2 \mathrm{~mm}$, mostly occurring on the buccal aspect of implants. In group C, there were 6 instances of porcelain fracture. In Group B and Group C, patients experienced clenching and grinding after OVD increase, which subsided after 2-3 months. It was concluded that alteration of OVD was acceptable in patients undergoing implant therapy, but precautions should be made to prevent mechanical problems (porcelain fracture).

\section{Esthetic effects of increasing Occlusal Vertical Dimension}

Gross ${ }^{13}$ evaluated the effect of increasing occlusal vertical dimension on lower face height in dental students aged $26-40$ years. Mounted casts were used to fabricate complete-arch occlusal overlays on maxillary casts. Interincisal distances of 2, 4, 6, 8mm were used. Changes in lower face height were measured using standardized photographs with the use of facial reference markers. Using repeated measures ANOVA, a significant effect of increase in OVD was detected for lower face height in MIP or rest potion. Another interesting finding was that changes in lower face height were smaller than the degree of change in OVD. For mean MIP changes, a $8 \mathrm{~mm}$ increase in OVD resulted in a change of appximately $4 \mathrm{~mm}$.

The changes in lower face height were evaluated by dentists and non-dentists. Results indicate that percentage of correct evaluations of face height from unmarked photographs was approximately $50 \%$ as the interocclusal distance increased from 2-6mm. It was concluded that, "changes in OVD in fixed prosthodontics within the range of 2 to 6 
$\mathrm{mm}$ are unlikely to cause visually apparent changes in the soft tissue face height in the range of normal OVD.

Kamashita $^{35}$ evaluated the influence of lip support on the soft-tissue profile in 5 edentulous subjects using a 3D non-contact imaging system. Experimental record bases were fabricated with adjustable lip support. Five lip support conditions were tested: $R(0)$ : standard lip support (incisal edge position $10 \mathrm{~mm}$ anterior to the center of the incisive papilla); $\mathrm{R}(+5)$ : excessive lip support; $\mathrm{R}(-5)$ : deficient lip support; $\mathrm{R}(-) \mathrm{B}(+)$ : record base only, no lip support; $\mathrm{R}(-) \mathrm{B}(-)$ : no record base. The effect of wearing dentures was also evaluated. The mean nasolabial angle measurement with dentures in place was $102.5^{\circ}$, as opposed to $120.2^{\circ}$ without dentures in place. Upper lip - E-line (lst-E) measurements increased from $-10.7 \mathrm{~mm}$ to $-3.0 \mathrm{~mm}$ with dentures in place. Lower lip - E-line (lit-E) increased from $-8.7 \mathrm{~mm}$ to $-1.4 \mathrm{~mm}$ with dentures in place. Comparing lip support conditions, nasolabial angle measurements for $\mathrm{R}(0), \mathrm{R}(-5)$, and $\mathrm{R}(+5)$ were 107.1, 114.4, 96.0, respectively. Upper lip-E-line (lst-E) measurements for $R(0), R(-5)$, and $R(+5)$ were $-3.8 \mathrm{~mm},-5.7 \mathrm{~mm},-0.9 \mathrm{~mm}$, respectively. Lower lip-E-line (lit-E) measurements for $\mathrm{R}(0)$, $\mathrm{R}(-5)$, and $\mathrm{R}(+5)$ were $-0.7 \mathrm{~mm},-2.9 \mathrm{~mm},+2.0 \mathrm{~mm}$, respectively. Lip support also affected the position of the lower half of the nose, shifting the tip of the nose (prn) forward with increasing lip support.

In a follow-up study, the same group evaluated changes in lip forms with alteration of lip support and/or occlusal vertical dimension using experimental record blocks ${ }^{20}$. Ten edentulous subjects, aged $51-81$ years participated in this study. 3D facial images were collected using a 3D optical surface scanning system. Experimental record blocks (heat cured record bases with removable wax rims) were used to provide 3 types 
of lip support ( $+5 \mathrm{~mm}$; 0mm; $-5 \mathrm{~mm})$, and 2 types of OVD $(\mathrm{OVD}=0 \mathrm{~mm}$; OVD $=-5 \mathrm{~mm})$. Facial landmarks at: labrale superior (ls); stomion (sto); labrale inferior (li); right/left oral fissure points (r-OFP/l-OFP) were evaluated. Research subjects were measured at a relaxed position with lips closed.

Comparing the effects of OVD change, the Y-axis position of ls (upper lip) and the average left to right oral fissure point measurements did not change significantly. However, the Y-axis position of stomion (sto) significantly shifted upward (by appx $1.5 \mathrm{~mm}$ ) with a $-5 \mathrm{~mm}$ change in OVD; the Y-axis position of the lower lip (1s) also significantly shifted upward (by appx $1 \mathrm{~mm}$ ) with a $-5 \mathrm{~mm}$ change in OVD. The authors concluded that with a change in OVD, only landmarks for sto and li shifted anterosuperiorly, whereas other landmarks only shifted only anteriorly. Extensive lip support (OVD at $0 \mathrm{~mm}$ with $+5 \mathrm{~mm}$ lip support) shifted landmarks forward, and deficient lip support shifted landmarks backward. With respect to oral fissure form, only subtle differences were found. No significant differences were found in commissural widths between any of the groups except for a significant decrease in commissural width when OVD +0 and $+5 \mathrm{~mm}$ lip support were utilized.

Mohindra $^{36}$ studied the effect of increasing vertical dimension of occlusion on facial esthetics in complete denture wearers. Questionnaires were sent to patients who had undergone complete denture therapy. Utilyzing acrylic pivots on either a training plate or the existing denture, the OVD was increased temporarily. The amount of vertical increase "took into account the golden proportion rule for facial esthetics". No mention was made as to the degree of occlusal vertical dimension increase. In addition, no control group was included in the study. In total, 69 out of 96 patients answered the 
questionnaire. $79 \%$ of these patients thought that treatment had made them look younger. In addition, $90.6 \%$ noted improvements to the lips; $87.5 \%$ noticed improvements to the jawline; $62.5 \%$ noticed improvements to the chin; $28.1 \%$ noticed improvements to the skin and eyes; $25 \%$ noticed improvements to the nose. Similar improvements were noted from a panel of laypersons and one dentist.

\section{Determination of Incisal Edge Position}

Vig and Brundo ${ }^{11}$ evaluated anterior tooth display at rest in subjects grouped by age and by sex. The average maxillary incisor display in men and women were $1.91 \mathrm{~mm}$ and $3.40 \mathrm{~mm}$, respectively. Men displayed $1.23 \mathrm{~mm}$ of mandibular incisors, and women displayed $0.49 \mathrm{~mm}$. People with short upper lips displayed more maxillary tooth structure. As the length of the upper lip increased, the amount of mandibular incisor exposure increased. The variability of age was evaluated by dividing the subjects into age groups of: under $29 ; 30-39 ; 40-49 ; 50-59 ; 60$ and older. The amounts of maxillary central incisor exposure in repose for these groups were: $3.37 \mathrm{~mm} ; 1.58 \mathrm{~mm} ; 0.95 \mathrm{~mm} ; 0.46 \mathrm{~mm}$; $0.04 \mathrm{~mm}$, respectively.

Frush and Fisher ${ }^{8}$ outlined their concept of fabricating esthetic dentures, termed the "dynesthetic technique". The word "dynesthetic" is different from "esthetic" in that "esthetic" is too abstract, and is applicable to anyone's interpretation. The word "esthetic" does not suffice because it does not identify the intent of the effort. The authors came up with the word "Dynesthetic" to imply the "movement, action, change, and progression in the esthetic phase of prosthodontics".

A summary of the dynesthetic procedure is as follows: 
1) Shade selection: Young teeth have a blue incisal edge with a yellowish body.

Depending on oral habits, older persons may have teeth which are lighter or darker than young people.

2) Mold selection: Molds are selected from a variety of criteria, including personality, age, masculinity or femininity. Shaping of the teeth may be needed to simulate abrasion or erosion.

3) Lip support: Maxillary anterior teeth may need to be moved more anterior from the most mechanically stable position to provide adequate lip support

4) Midline: The dental midline does not need to be coincident with the facial midline, as long as the long axis is vertical.

5) Speaking line: The vertical position of the incisor edges are dependent on the age and gender of the patient. For example, an incisal edge position $3 \mathrm{~mm}$ below the lip line at rest may be selected for a young woman, and an incisal edge position of 0mm may be selected for an old man.

6) Smiling line: a sharper arc gives a more youthful appearance, and a broader curve gives an older appearance.

7) Central incisor position Central incisors may be placed ahead or behind one another. Size contrast against the lateral incisor, and grinding of the edge may also be used as needed

8) Lateral incisor position: The rotation of the lateral incisors may give a softer or harder appearance

9) Cuspid position: The incisal edges of the cuspids should be abraded according to the age of the patient 
10) Spaces: Diastimas may be incorporated as needed.

11) Embrasures: There should be no separation of the proximal surfaces in posterior teeth

12) Buccal corridor: The author advocates not eliminating the buccal corridor, since this may lead to a "sixty tooth smile" appearance, which is characteristic of a denture 13) Long axes/Gum line/Interdnetal papilla: These factors may also be manipulated to give an older or younger appearance. For example, the interdental papilla for older persons should be wider and shorter than that of younger persons.

14) Lingual cutaway/Labial and buccal denture base contour: These factors are important to eliminate food trapping, and for facial esthetics.

Misch $^{12}$ evaluated 104 dentate Caucasian patients between the ages of 30 and 59. Measurements were made by having the patients say "emma", and then relax. A ruler measured the distance between the upper lip in repose and the upper right central incisor. Another measurement was made between the canine tip and the maxillary lip in repose. The vertical exposure of the maxillary central incisor at repose for females averaged $3.8 \mathrm{~mm}$ (range $-1 \mathrm{~mm}$ to $+8 \mathrm{~mm}$ ); for males, it averaged $2.5 \mathrm{~mm}$ (range -3 to $+7 \mathrm{~mm}$ ). The vertical exposure of the maxillary canine for females averaged $0 \mathrm{~mm}$ (range $-2 \mathrm{~mm}$ to $+2 \mathrm{~mm}$ ); for males, it averaged $-0.5 \mathrm{~mm}$ (range $-3 \mathrm{~mm}$ to $+2 \mathrm{~mm}$ ). The narrower ranges found for maxillary canines led the author to conclude that relative to the maxillary lip, the position of the maxillary canine was more predictable than the maxillary central incisor.

Turner and Missirlian ${ }^{3}$ classified excessive tooth wear into three categories:

1) Excessive wear with loss of occlusal vertical dimension 
Patients in this category is typically missing a few posterior teeth, has unstable posterior occlusion, and has extremely worn anterior teeth. The author suggested that the only way to confirm that OVD has been lost is to fabricate trial restorations and worn for 6-8 weeks. The patient is evaluated for acceptance of the new OVD using removable occlusal overlay splints, teeth may be prepared and provisionalized.

2) Excessive wear without loss of occlusal vertical dimension but with space available

Patients in this category have posterior support, and have had a long history of wear. These patients typically demonstrate an interocclusal distance of 2-3mm and a closest speaking space of $1 \mathrm{~mm}$. There may be a significant slide from centric to maximum intercuspation. Development of a physiologic occlusion is critical in these cases. Surgical crown lengthening may be needed to gain clinical crown length.

3) Excessive wear without loss of occlusal vertical dimension with limited space Patients in this category typically have posterior teeth that show minimal wear, but anterior teeth that have excessive wear. These patients typically demonstrate an interocclusal distance of $2-3 \mathrm{~mm}$, and a closest speaking space of $1 \mathrm{~mm}$. Centric relation and maximum intercuspation are generally coincident. For these cases, orthodontic movement may be necessary to intrude the anterior teeth, or to move the teeth facially to create space. Block surgical repositioning such as LeFort I procedures may also be performed. 


\section{CHAPTER III}

\section{MATERIALS AND METHODS}

Approval for this study was obtained from the Marquette University School of Dentistry Institutional Review Board (IRB). Inclusion and exclusion criteria are summarized in Table 1. Inclusion criteria include: 1) 21 -39 years of age; 2) voluntary involvement in the study; 3) no missing anterior teeth; 4) at least 3 teeth in occlusion in both posterior segments. Exclusion criteria include: 1) history of surgery in the facial area; 2) history of neurologic disorders; 3) CO-CR discrepancy >1 mm; 4) inability or unwillingness to smile; 4) persisting ear infections; 5) allergy to silicone, nitrile, or alginate; 6) history of claustrophobia. Thirty dental students, 12 male and 18 female, mean age: 23.8 years, range: $21-30$, were recruited for this study. Dental students were invited to participate in this study following a brief presentation on the study. Other dental students were invited to participate in this study via email. All participants were free from neurological or surgical problems in the facial area which would inhibit normal smiling. Twenty one participants had a prior history of orthodontics (Table 2). 


\begin{tabular}{|l|l|}
\hline Inclusion Criteria & Exclusion Criteria \\
\hline $21-39$ years of age & History of surgery in the facial area \\
\hline Voluntary involvement in the study & History of neurological disorders \\
\hline No missing anterior teeth & CO-CR discrepancy $>1 \mathrm{~mm}$ \\
\hline $\begin{array}{l}\text { At least } 3 \text { teeth in occlusion in both posterior } \\
\text { segments }\end{array}$ & Inability or unwillingness to smile \\
\hline & Persisting ear infections \\
\hline & Allergy to silicone, nitrile, or alginate \\
\hline & History of claustrophobia \\
\hline
\end{tabular}

Table 1: Inclusion and exclusion criteria

\begin{tabular}{|l|l|}
\hline Age & Mean: 23.8 years Range: $21-30$ \\
\hline Gender & Female: 18 Male: 12 \\
\hline Ethnicity & Caucasian: 25 \\
& Latino: 3 \\
& Arabic: 1 \\
& Asian Indian: 1 \\
\hline History of Orthodontics & $21 / 30$ \\
\hline Angle's Classification & Class I: 29 \\
& Class II: 0 \\
& Class III: 1 (unilateral molar Class III) \\
\hline
\end{tabular}

Table 2: Description of the study sample

The study was conducted in two sessions. In session 1, informed consent was obtained, a questionnaire was filled out (Appendex 1 and Appendex 2), and a limited oral examination was conducted to determine whether the research participant fits the inclusion/exclusion criteria. The number of teeth in occlusion was checked, and CO-CR discrepancy was verified using chin point guidance.

Irreversible hydrocolloid impressions were taken (ImprESSIX Color Change, Dentsply) using metal stock trays. Arbitrary hinge facebow transfers were obtained (Pana-Mount, Panadent). Silicone bite registrations in maximum intercuspation were also obtained (Imprint Bite, 3M ESPE).

The impressions were poured in a type III dental stone (Microstone Golden, Whip-Mix). After trimming and indexing, the poured casts were articulated on semiadjustable articulators (PCH, Panadent). The silicone bite registrations were used to 
facilitate accurate positioning of the maxillary and mandibular casts, but were not used for the actual articulation procedure.

Lines were drawn approximately $1 \mathrm{~mm}$ apical to the CEJs of tooth \#9 and tooth \#24. The vertical distance between these two lines was measured using a digital caliper (500-170, Mitutoyo). This position was used to open the articulator $+2 \mathrm{~mm},+4 \mathrm{~mm}$, $+6 \mathrm{~mm},+8 \mathrm{~mm}$ to obtain the correct posterior openings. At these openings, silicone bite registration material (Imprint Bite, 3M ESPE) was injected onto the occlusal surfaces from $1^{\text {st }}$ premolar to $2^{\text {nd }}$ molar. These bite registrations were used as bite splints to obtain the desired openings in occlusal vertical dimension. Bite splints for $+0 \mathrm{~mm}$ were not made. The bite splints were trimmed in the following manner:

1) the top portion was trimmed so that the indentations of the maxillary cusp tips were approximately $1 \mathrm{~mm}$ deep

2) the buccal surface of the top portion was trimmed to the depth of the facial cusp tips. This enabled visualization of complete seating of teeth into the indentations.

3) the bottom portion was trimmed to cover up to the CEJ of the mandibular teeth. This provided some stability to the bite splints to the mandibular teeth.

The bite splints were disinfected (CaviCide, Kerr) and stored in color coded plastic bags. The following color codes were used for the various bite splints:

Blue- 0mm

Red- $2 \mathrm{~mm}$

Purple- $4 \mathrm{~mm}$

Yellow- 6mm

Green- $8 \mathrm{~mm}$ 
Since no bite splints were made for the 0mm group, the "blue" plastic bags were left empty.

The sequence of insertion of the bite splints was determined using a random number generator (www.random.org).

During the $2^{\text {nd }}$ session, 3 photographs each were taken with the various bite splints in place (Figure 2). In order to obtain a standardized head position, a wallmounted cephalometric head holding device (Accu-Ceph, Denar) was modified for head positioning (Fig 1). A right-angle metal plate (a metal bookend) was attached to the side plate of the head holding device, and a plastic ruler was adhered to the end of the metal plate. This allowed the ruler to be set at a fixed distance from the participants' faces. As the participants' faces had varying dimensions, custom orbital pointers of varying lengths were fabricated to permit the orbital pointer to lightly touch the infraorbital notch. Following verification of head tilt, the orbital pointer was moved away from the face to permit uninhibited movement. 


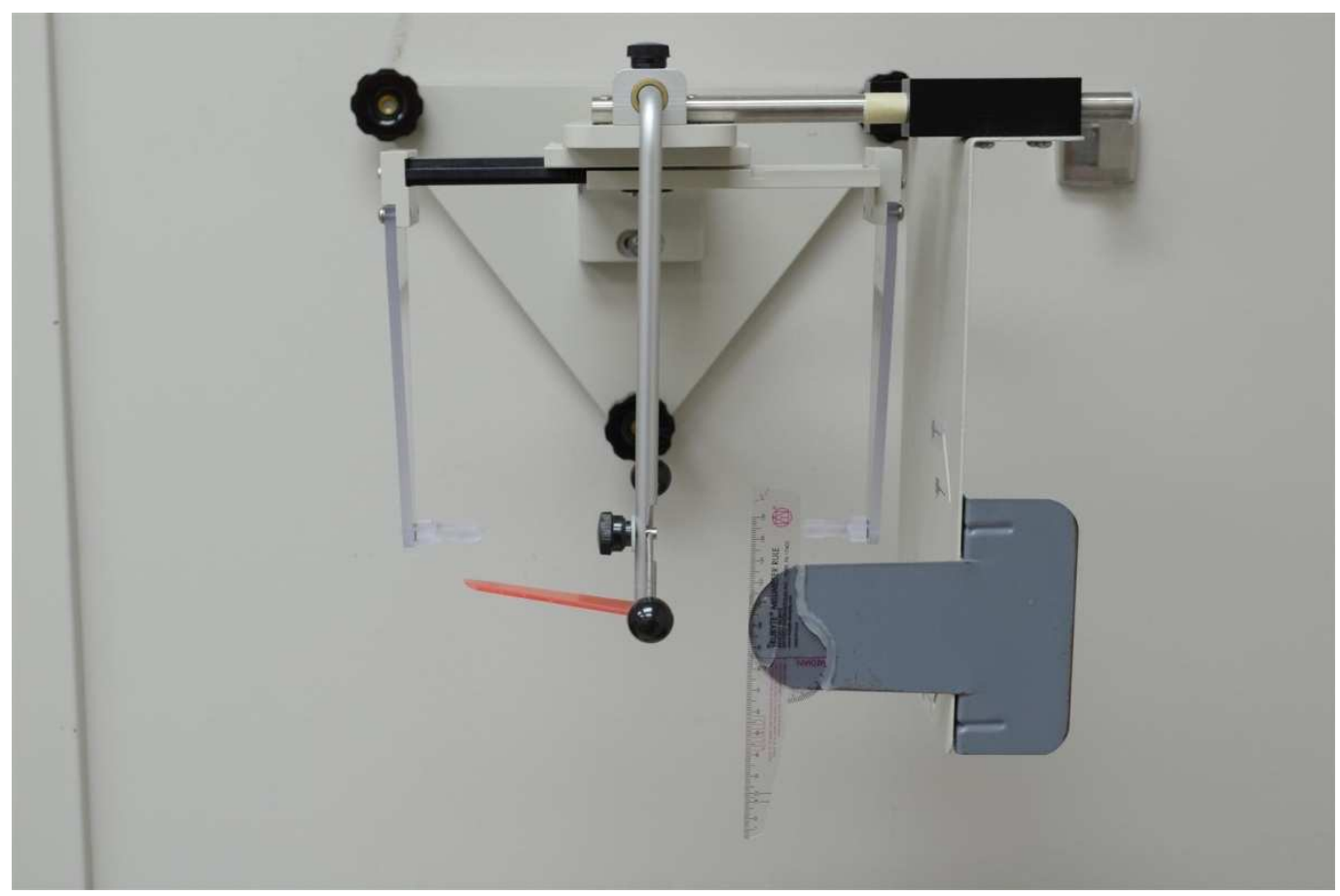

Figure 1 Head positioning apparatus

A digital single reflex camera (D7000, Nikon) with macro lens (Micro-NIKKOR $105 \mathrm{~mm}$ f/2.8VR, Nikon) was used for photographic data acquisition. The camera was mounted on a tripod (055XPROB with 496RC2, Manfrotto). For accurate positioning of the tripod between sessions, the tripod was secured to the floor using a hot glue gun (GR20K, Stanley). The horizontal tilt of the camera was checked using the camera's "digital level tool". The anterior-posterior tilt was checked using a bubble gauge. The camera was connected to a laptop computer with camera control software (Camera Control Pro 2, Nikon). The camera control software permitted real-time visualization of the photographs taken. For the second session, the experiment was conducted by two operators. One operator positioned bite splints, and adjusted head positions, while the other operator took the photos (directly from the laptop computer) and checked for discrepancies in the photos. If an obvious discrepancy in a particular set of 3 photographs 
was seen, the 3 photographs were re-taken. Reasons for obvious discrepancies include: laughter, drooling, head movement. Approximately 10 sets of photographs were re-taken. For positioning, the subject's right infra-orbital notch was marked with a black marker. The subjects' head tilt was subsequently adjusted to this vertical level. The head tilt adjustment was conducted for each set of pictures ( 5 times for each subject). The nasion relator was not used, so as not to impinge on facial muscles during smiling. The subjects were asked to close gently on the back teeth, say, "M, M, M", relax, and smile. A photograph was then taken at the posed smile. The subjects were again asked to say, “M, M, M”, relax, and smile, and another photograph was taken. This procedure was repeated for the third photograph. The three photographs were verified for obvious discrepancies, file names were renamed, and the bite splint was replaced. The sequence of the placement of bite splints was randomized, and the individual groups were referred to as the color codes (blue, red, yellow, etc.), instead of the vertical openings. This was done to blind the subjects as to which vertical opening was used. At the 0mm OVD opening, the same instructions were given, but no bite splint was placed. Following replacement of the silicone bite splints, the head tilt was again verified using the orbital pointer, and the sequence was repeated. 


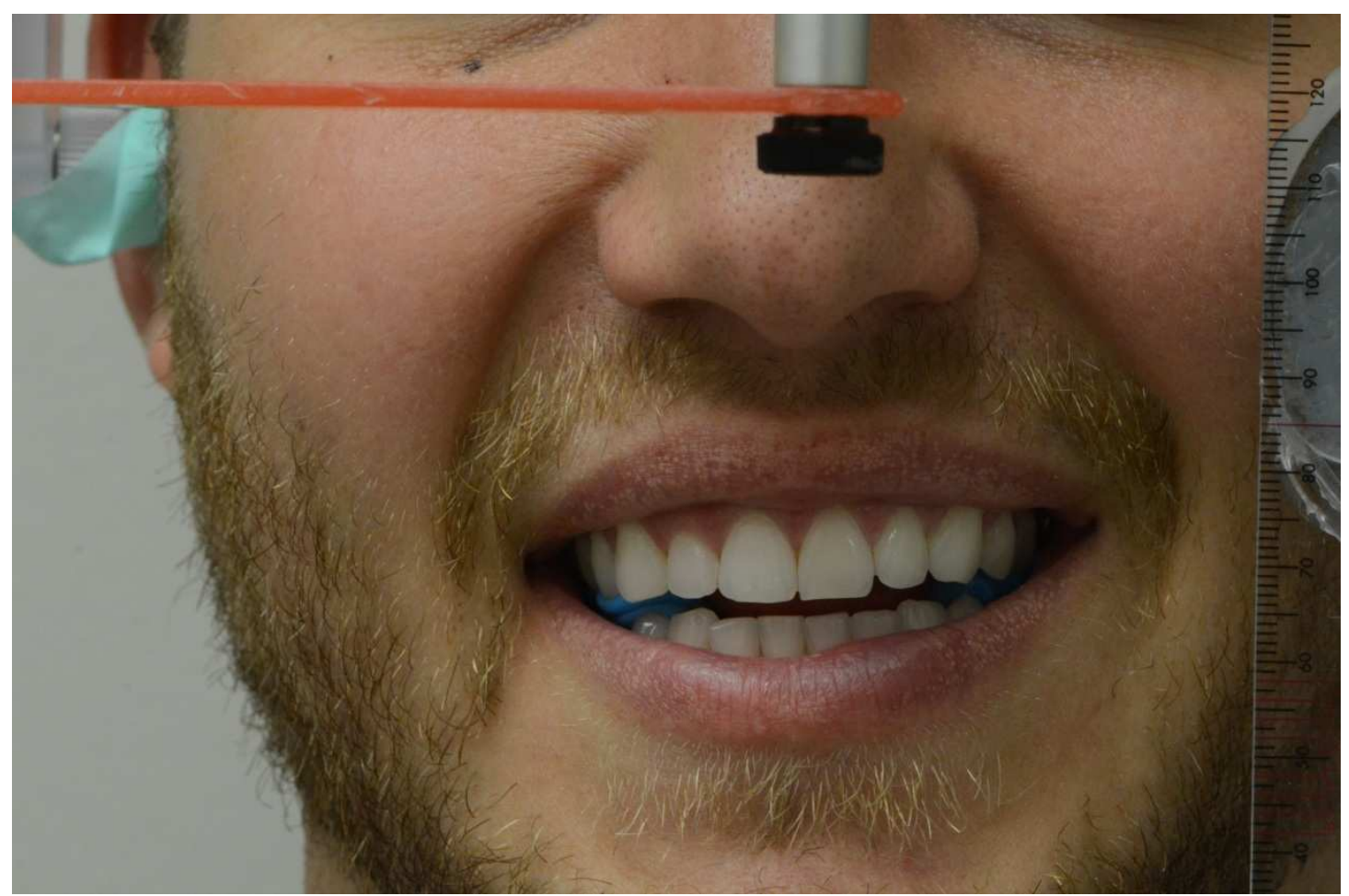

Figure 2 Representative photograph of the smile (at $+2 \mathrm{~mm}$ OVD) 


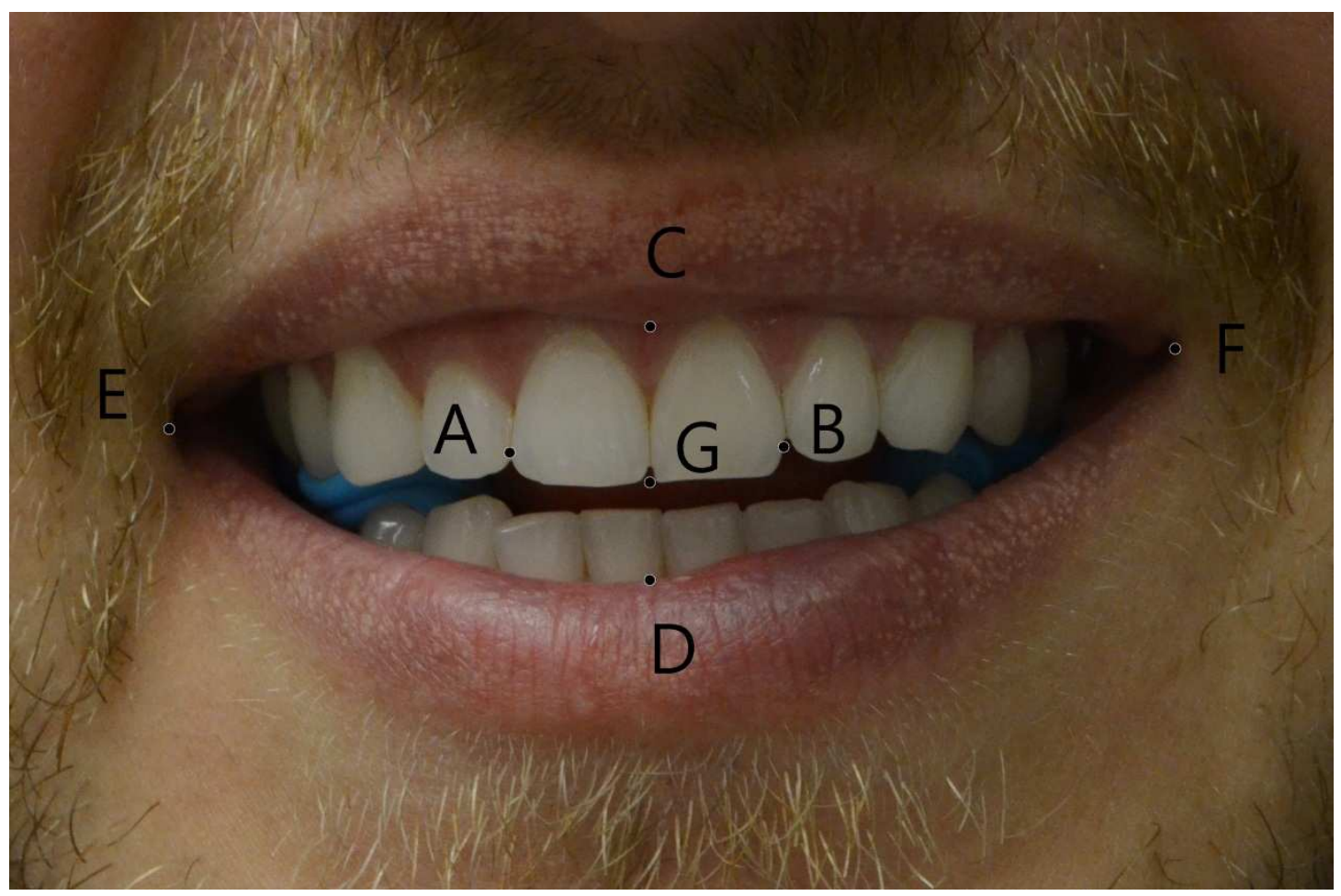

Figure 3 Points of measurement

8-9 Width: A-B

Interlabial gap height: C-D

Intercommisural Width: E-F

Incisal edge - Upper lip: G-C

Incisal edge - Lower lip: G-D 
The photographs were imported into Adobe Photoshop (Photoshop CS5, Adobe), and the following measurements were made (Figure 3):

1) 8-9 width

2) Interlabial gap height: The vertical distance between the upper and lower lips, intersecting the midpoint of the incisal embrasure between 8 and 9 .

3) Intercommisural width: Distance between left and right commisures

4) Incisal edge - Upper lip: The vertical distance between the midpoint of the incisal embrasure between 8-9 and the upper lip

5) Incisal edge - Lower lip: The vertical distance between the midpoint of the incisal embrasure between $8-9$ and the lower lip

The measurements were made in pixels.

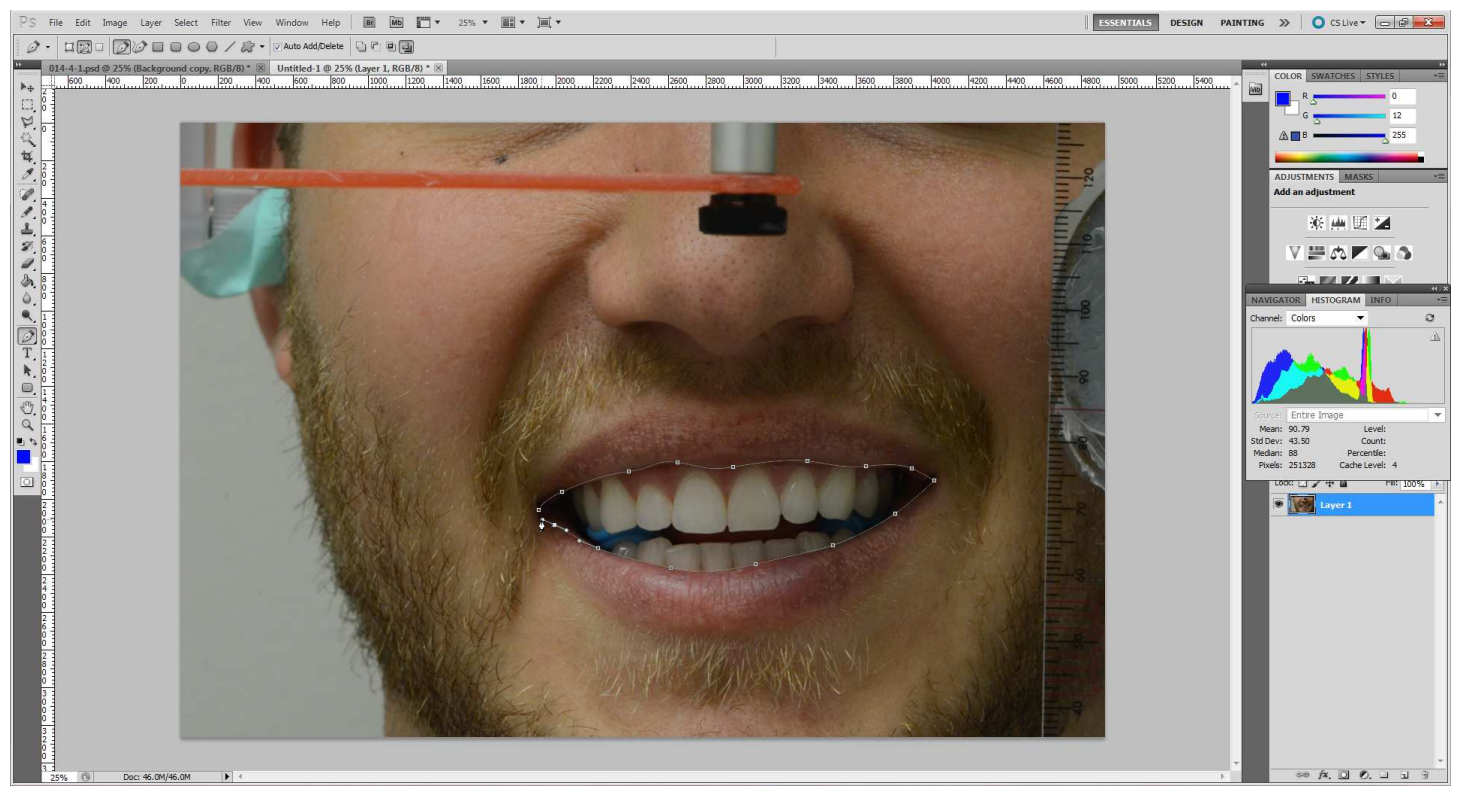

Figure 4 Display zone area tracing 
The outline of the interior border of the display zone was traced using the Pen tool, and this area was recorded in pixels (Figure 4).

On the stone model, the width of 8-9 was measured using a digital caliper, and recorded in millimeters. This distance was measured three times to obtain an average 8-9 measurement. The average measurement of 8-9 in pixels (from 15 photographs) was divided with the average measurement of 8-9 in millimeters to obtain a conversion ratio for each individual subject. The conversion ratio was used to convert the measurements in pixels to millimeters.

For photographs in which the incisal embrasure between 8-9 is covered by the lower lip, the next photograph in the sequence in which the incisal embrasure is not covered by the lip is superimposed onto the original photograph, to determine the correct position of the midpoint of the incisal embrasure.

\section{Statistical Analysis}

One examiner (J.C.) conducted all 8,190 measurements. These measurements were recorded in Microsoft Excel (Excel 2010, Microsoft), and statistical analysis was conducted using SPSS (SPSS 21, IBM).

One-way repeated measures analysis of variance (ANOVA) was used at an alpha level of 0.05 . The main effect was occlusal vertical dimension, with 5 levels: $+0 \mathrm{~mm}$, $+2 \mathrm{~mm},+4 \mathrm{~mm},+6 \mathrm{~mm},+8 \mathrm{~mm}$. If a statistically significant difference was found, pairwise comparisons were made using Bonferroni corrected paired t tests. 


\section{CHAPTER IV}

\section{RESULTS}

The results of this study are shown in Tables 3 and 4 .

For interlabial gap height, the mean measurement at OVD +0mm was $10.42 \pm$

$3.28 \mathrm{~mm}$. A statistically significant difference $(\mathrm{P}<0.001)$ was found with increasing occlusal vertical dimensions. Pairwise comparisons using Bonferroni corrected paired-t tests revealed all groups to be significantly different from each other $(\mathrm{P}<0.01)$.

For intercommisural width, the mean measurement at OVD $+0 \mathrm{~mm}$ was $62.90 \pm$ 4.17mm. No statistically significant difference was found with increasing OVD $(\mathrm{P}=0.352)$.

For Incisal edge to upper lip length, the mean measurement at OVD +0mm was $8.20 \pm 2.22 \mathrm{~mm}$. No statistically significant difference was found with increasing OVD $(\mathrm{P}=0.484)$

For Incisal edge to lower lip length, the mean measurement at OVD +0mm was 2.28mm. A statistically significant difference was found with increasing OVD $(\mathrm{P}<0.001)$. Pairwise comparisons revealed all main measures to be statistically significant with each other $(\mathrm{P}<0.005)$

For internal display zone area, the mean measurement at OVD +0 was $509.08 \pm$ $190.08 \mathrm{~mm}^{2}$. A statistically significant difference was found with increasing OVD 
$(\mathrm{P}<0.001)$. Pairwise comparisons revealed all groups to be significantly different from each other $(\mathrm{P}<0.01)$, with the exception of OVD +4 with OVD $+6(\mathrm{P}=0.064)$.

Individual measurements are presented in Figures 5 through 9. The color lines represent individual subject measurements. 


\begin{tabular}{|c|c|c|c|c|}
\hline Measurement & OVD & Mean & SD & $\begin{array}{l}\mathrm{P} \text { value (Greenhouse- } \\
\text { Geisser) }\end{array}$ \\
\hline \multirow[t]{5}{*}{ Interlabial Gap Height } & 0 & 10.42 & 3.28 & $<0.001$ \\
\hline & 2 & 12.47 & 3.97 & \\
\hline & 4 & 13.48 & 4.52 & \\
\hline & 6 & 14.35 & 4.37 & \\
\hline & 8 & 15.45 & 4.71 & \\
\hline \multirow[t]{5}{*}{ Intercommisural Width } & 0 & 62.90 & 4.17 & 0.352 \\
\hline & 2 & 62.54 & 4.47 & \\
\hline & 4 & 62.78 & 4.12 & \\
\hline & 6 & 62.46 & 4.09 & \\
\hline & 8 & 62.22 & 4.50 & \\
\hline \multirow[t]{5}{*}{ Incisal Edge - Upper Lip } & 0 & 8.20 & 2.22 & 0.484 \\
\hline & 2 & 8.33 & 2.43 & \\
\hline & 4 & 8.19 & 2.49 & \\
\hline & 6 & 8.18 & 2.47 & \\
\hline & 8 & 8.03 & 2.62 & \\
\hline \multirow[t]{5}{*}{ Incisal Edge - Lower Lip } & 0 & 2.28 & 1.99 & $<0.001$ \\
\hline & 2 & 4.14 & 2.52 & \\
\hline & 4 & 5.29 & 2.95 & \\
\hline & 6 & 6.15 & 2.89 & \\
\hline & 8 & 7.45 & 3.40 & \\
\hline \multirow[t]{5}{*}{ Display Zone Area } & 0 & 509.08 & 190.08 & $<0.001$ \\
\hline & 2 & 612.61 & 228.35 & \\
\hline & 4 & 659.66 & 252.08 & \\
\hline & 6 & 696.00 & 244.14 & \\
\hline & 8 & 742.94 & 261.52 & \\
\hline
\end{tabular}

Table 3: Results for smile measurements 


\begin{tabular}{|l|l|l|l|l|l|}
\hline Source (OVD) & $\begin{array}{l}\text { Type III } \\
\text { Sum of } \\
\text { Squares }\end{array}$ & df & $\begin{array}{l}\text { Mean } \\
\text { Square }\end{array}$ & F & P \\
\hline $\begin{array}{l}\text { Interlabial Gap } \\
\text { Height }\end{array}$ & 441.816 & 2.637 & 167.572 & 101.378 & $<0.001$ \\
\hline $\begin{array}{l}\text { Intercommissural } \\
\text { Width }\end{array}$ & 8.697 & 3.310 & 2.627 & 1.110 & .352 \\
\hline $\begin{array}{l}\text { Incisal Edge - } \\
\text { Upper Lip }\end{array}$ & 1.344 & 3.307 & .407 & .841 & .484 \\
\hline $\begin{array}{l}\text { Incisal Edge - } \\
\text { Lower Lip }\end{array}$ & 466.139 & 2.287 & 203.812 & 115.231 & $<0.001$ \\
\hline $\begin{array}{l}\text { Internal Display } \\
\text { Zone Area }\end{array}$ & 957855.215 & 2.805 & 34151.006 & 62.685 & $<0.001$ \\
\hline
\end{tabular}

Table 4: Results of one-way repeated measures ANOVA (Greenhouse-Geisser Test) 


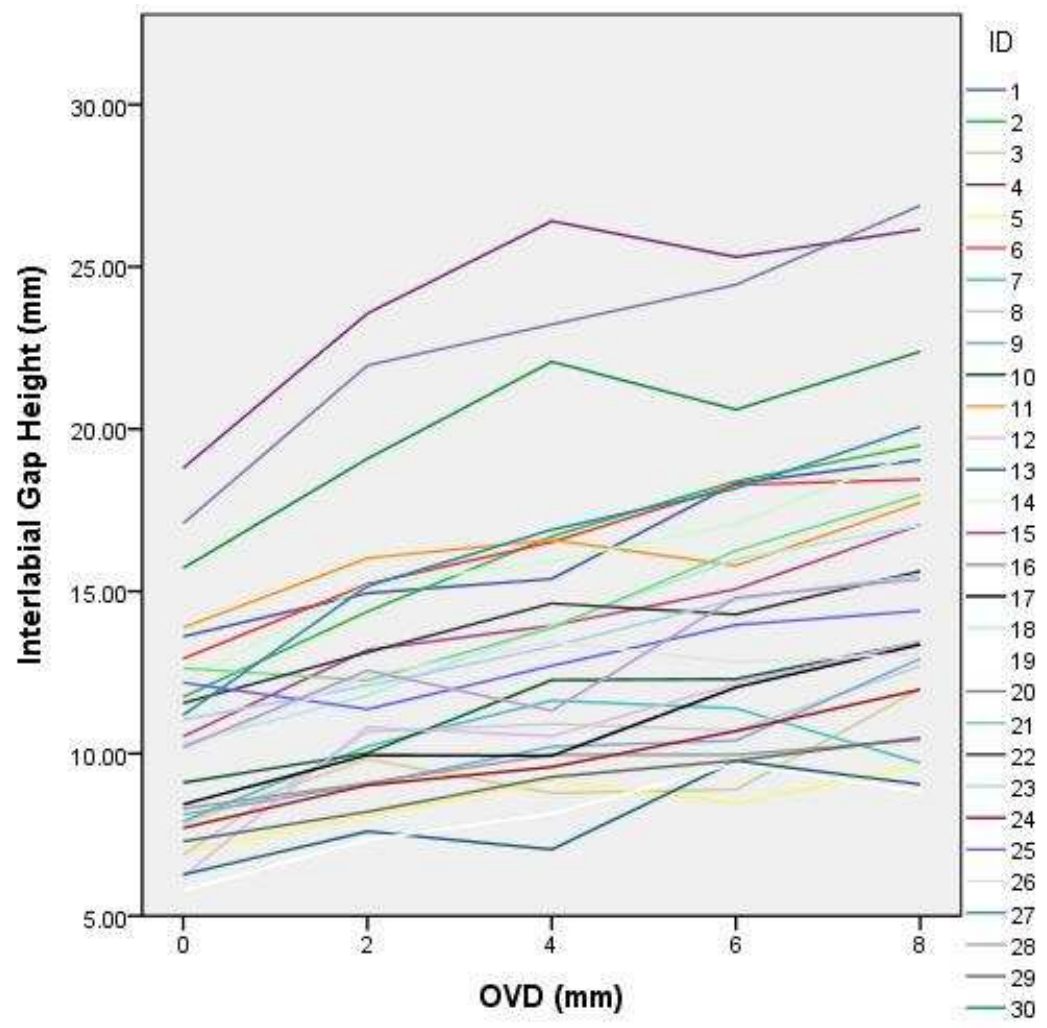

Figure 5 Individualized data for interlabial gap height 


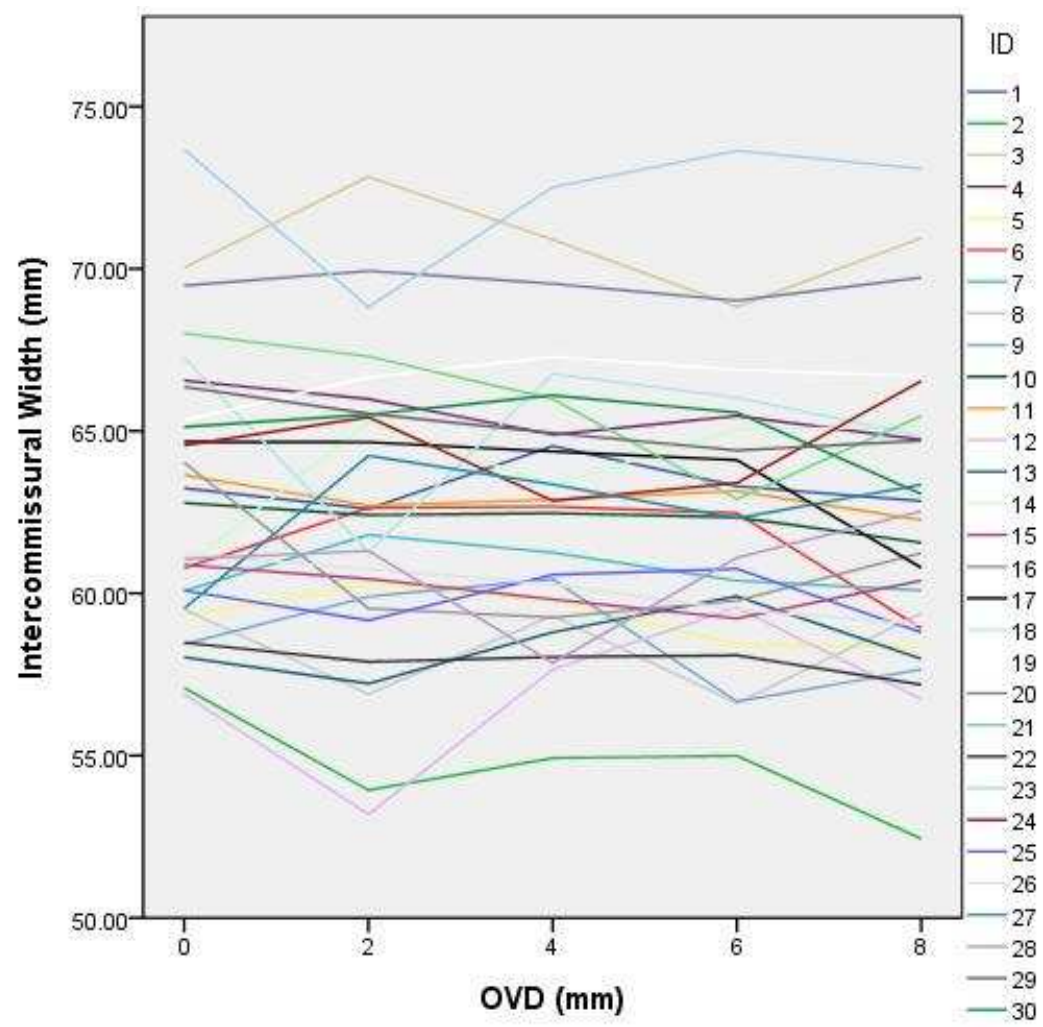

Figure 6 Individualized data for intercommisural width 


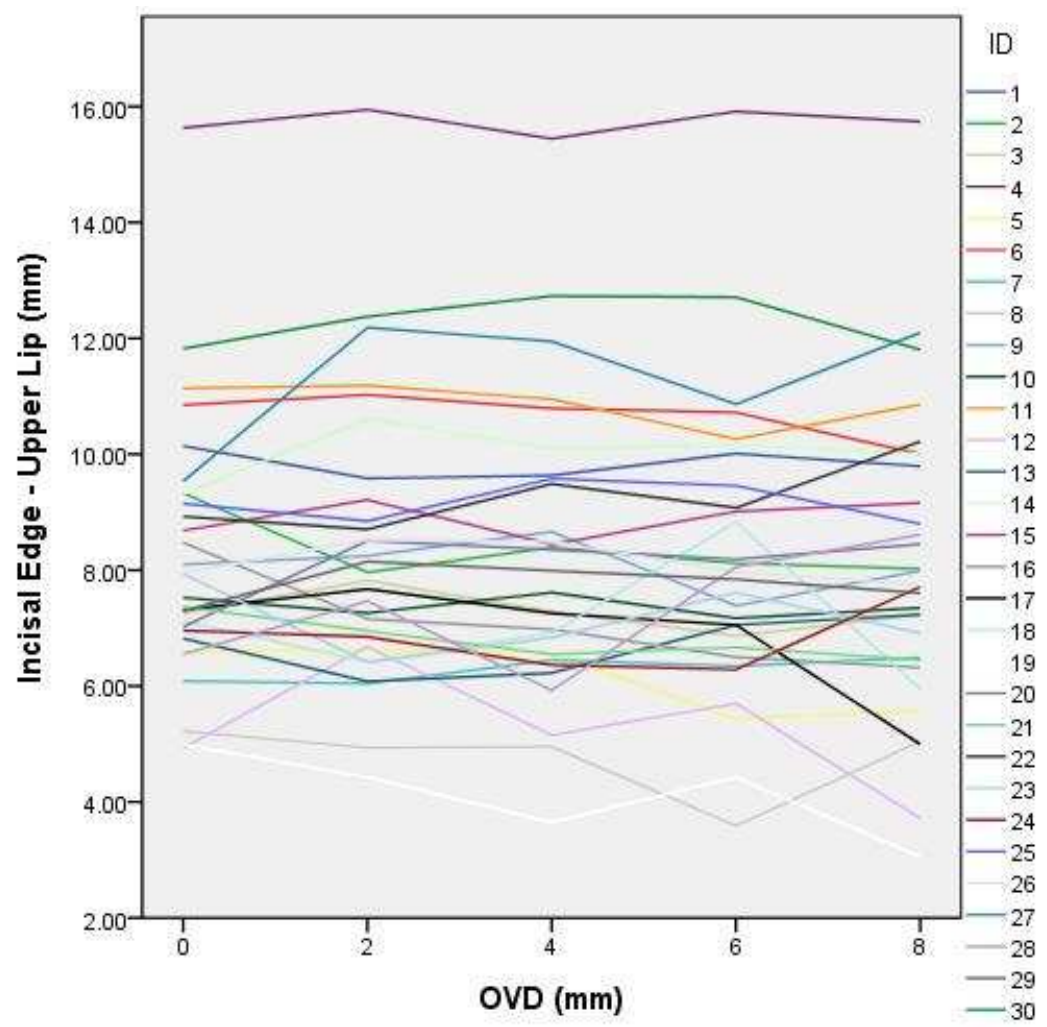

Figure 7 Individualized data for Incisal edge - Upper lip 


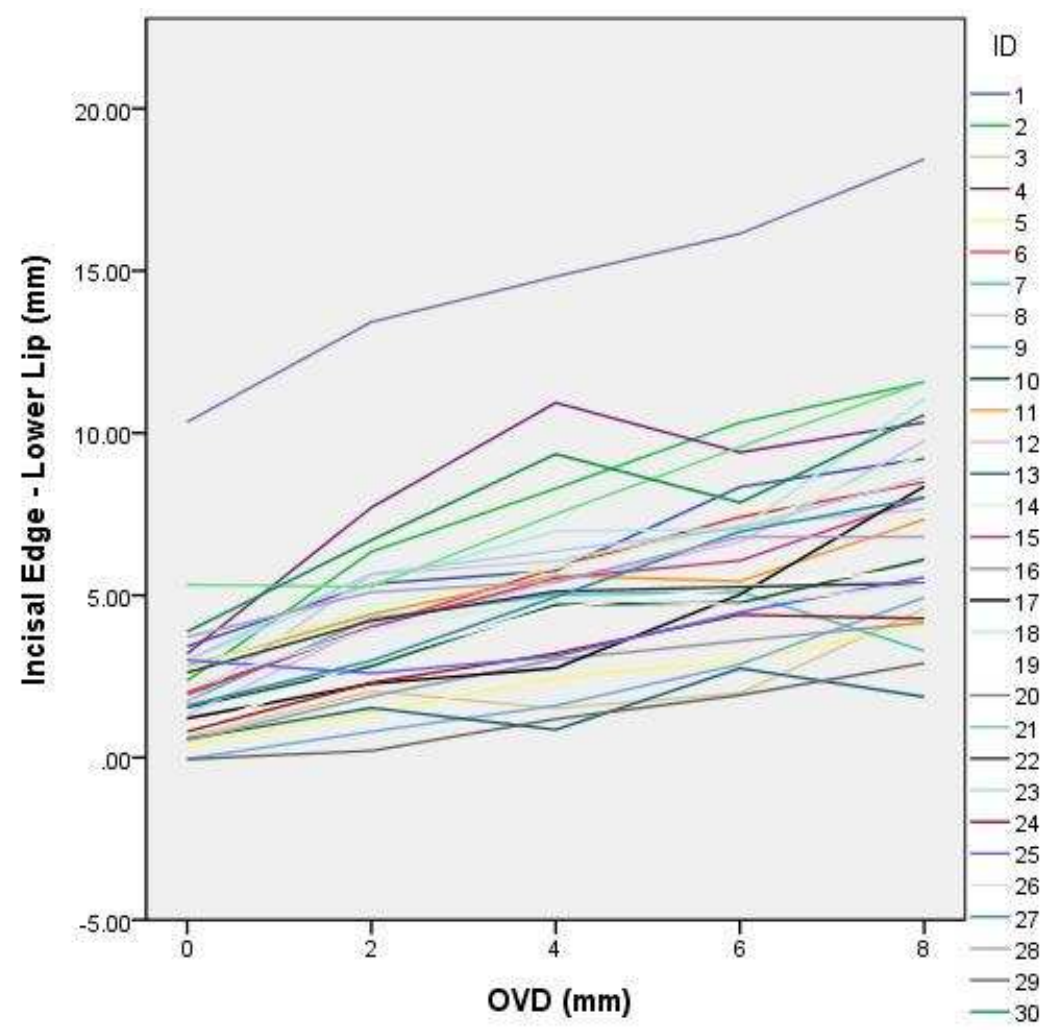

Figure 8 Individualized data for Incisal edge - Lower lip 


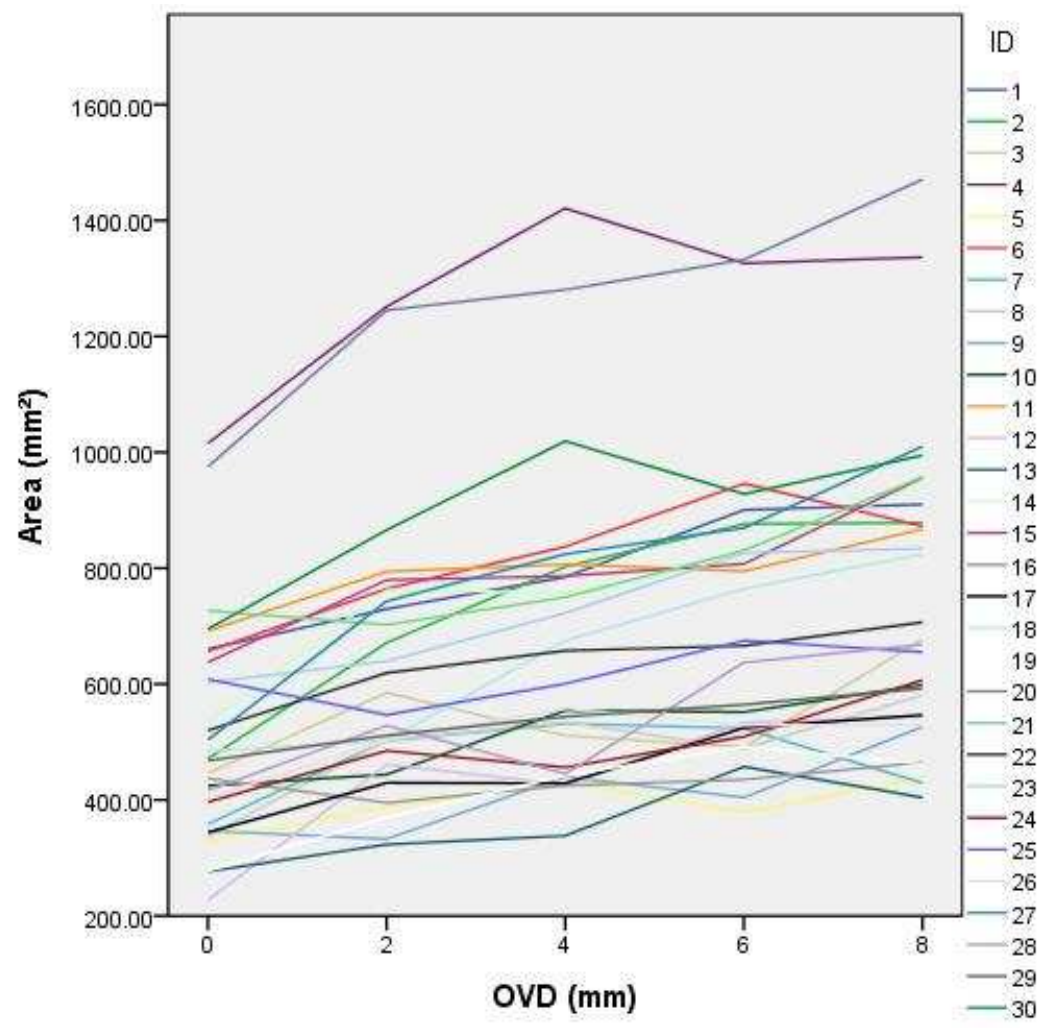

Figure 9 Individualized data for display zone area 


\section{CHAPTER V}

\section{DISCUSSION}

In this study, we have utilized a photographic method for smile analysis, using the width of the maxillary central incisors to calibrate the photographic measurements. This technique is similar to the method by $\mathrm{Hu}^{14}$, who used crown length for calibration. A videographic method was not selected because of the higher resolution that can be obtained from still images. The resolution of the images obtained from the digital single reflex camera in the present study was 4928 x 3264 pixels. This provides a more detailed image than can be captured using modern 1080p video cameras, which capture video at 1920 x 1080 pixels. Standard 480i video equipment used in past studies by Ackerman, Desai , McNamara and others capture video at 640 x 480 pixels. ${ }^{9,15,16}$ A recent study by McNamara also found no statistically significant differences between smiles captured by video and photographic techniques. ${ }^{37}$

The esthetic effects of increase in OVD have not been extensively studied. Currently, there have only been reports on the effects of OVD increase to lower facial height and soft tissues at rest. To the best of our knowledge, this has been the first study to evaluate the effects of OVD increase on the smile.

In the present study, a change of $+8 \mathrm{~mm}$ in OVD yielded a $+5.0 \mathrm{~mm}$ change in interlabial gap height, and a $+5.2 \mathrm{~mm}$ change in incisal edge - lower lip distance at smile. These findings were similar to findings by Gross ${ }^{13}$, who found a $+4 \mathrm{~mm}$ change in lower face height with $+8 \mathrm{~mm}$ change in OVD. It is likely that this finding is a combination of several factors. First, change in OVD is measured from CEJ - CEJ, which is not 
perpendicular to the "line of sight" of the photograph taken. This change in angulation may cause a slight discrepancy in the measured vertical distances. The angle between CEJ-CEJ and the line of sight also increases as OVD is increased, yielding less vertical change for each progressive increment of OVD. Secondly, soft tissue changes are likely to occur to a lesser degree than hard tissues. Soncul and Bamber ${ }^{38}$ evaluated the soft tissue changes after orthognathic surgical correction of Class III deformities and found a $50 \%$ to $70 \%$ change in upper and lower vermillion borders in comparison to changes in hard tissue profile. Kamashita ${ }^{35}$ found similar results using wax rims with variable amounts of lip support. With a $5 \mathrm{~mm}$ facial addition to the upper and lower wax rims, a gain of $2.9 \mathrm{~mm}$ was observed in the upper lip relative to the E-line. Other factors, such as the variability of contractile forces at different muscle lengths may also play a role.

The importance of the position of the upper lip at smile has been well documented in the literature. $\operatorname{Tjan}^{10}$ defined the "average smile" as one that reveals $75 \%$ to $100 \%$ of the maxillary anterior teeth and interproximal gingiva. Hulsey ${ }^{5}$ found subjects who had an upper lip which was at the height of the gingival margin of the upper central incisor to be the most esthetically pleasing. Currently, the effect of OVD on upper lip position has not been studied. One case report claimed that increasing the vertical dimension increases the crown-to-gum ratio and effectively decreases the gummy smile. ${ }^{39}$ However, in the present study, no statistically significant change was found with respect to the upper lip at smile with increasing OVD. One possibility may be that individual differences or patient adaptability after an increased OVD accounted for the perceived lowering of the upper lip at smile observed in the case report. Another possibility may be that gingival recession following prosthetic treatment had occurred. Yet another possibility may be the common 
practice of taking a photograph with the patient's head tilted down. A recent study found that smile photographs with the camera situated above the plane of occlusion to yield more attractive photographs than a straight view or with the camera situated below the plane of occlusion. ${ }^{23}$ In any case, the results of the present study suggest that for treatment planning purposes, the upper lip at smile should not be expected to move down from increased OVD.

Ackerman ${ }^{15}$ described the "display zone" as the area framed by the upper and lower lips. The author described teeth and the gingival scaffold as components of the smile which lie within this display zone. The display zone area was quantified in the present study by outlining the internal area between the upper and lower lips at smile. A mean display zone area of $509 \pm 190 \mathrm{~mm}^{2}$ was found for the $+0 \mathrm{~mm}$ OVD group. The high standard deviation indicates a considerable amount of variability in display zone area among different subjects. A statistically significant increase was found in display zone area with increase in OVD, although no significance was found between the +4mm OVD and the $+6 \mathrm{~mm}$ OVD groups. Because the maxillary central incisal edge position is dictated by the maxillary lip in repose, an increase in display zone area could lead to an increase in the display of mandibular teeth. This may pose an esthetic compromise, since the patient may start to show "too many teeth", contrary to what is believed to be esthetically acceptable.

In the present study, 21 out of 30 subjects (70\%) had a history of previous orthodontic treatment. One epidemiological study found the prevalence of US children 918 years with at least one orthodontic visit to range from $14.3 \%$ to $16.8 \% .^{40}$ In the same study, racial and socioeconomic differences were found, with black children less likely to 
have made a visit compared to white children, even among children of high socioeconomic status. Another factor for this discrepancy may be that dental students were generally brought up in families that were more attenuated to dental health than the general public. This finding suggests that using dental students as research subjects, although convenient, may not be a good representation of the general public.

It should be noted that the present study has several major limitations. First, the age range of 21-30 years may not represent the typical prosthodontic patient. Significant discrepancies with respect to age should be anticipated. Second, the bulkiness and removable nature of the silicone bite splints may have negatively influenced the smile. In addition, since all of the data was collected in one sitting, the long term adaptation of the facial muscles could not be assessed. Finally, none of the subjects in the present study have lost OVD. It is likely that patients who have had extensive loss of tooth structure or loss of teeth will behave differently as OVD is restored. Further studies are necessary to provide a clear understanding of the long term clinical implications for the effect of OVD change on the smile. 


\section{CHAPTER VI}

\section{CONCLUSIONS}

Within the limitations of this study, the following conclusions may be drawn:

1) Excessive increase of OVD may lead to excessive interlabial gap height, incisal edge lower lip length, and display zone area.

2) A lengthening of the upper lip at smile should not be expected with increase of OVD.

3) A change in the width of the smile should not be expected with increase of OVD. 


\section{BIBLIOGRAPHY}

1. Spear F. Approaches to vertical dimension. Adv Esthet Interdiscip Dent. 2006;2:2-12.

2. Keough B. Occlusion-based treatment planning for complex dental restorations: Part 1. Int J Periodontics Restorative Dent. 2003;23:237-47.

3. Turner KA, Missirlian DM. Restoration of the extremely worn dentition. J Prosthet Dent. 1984;52:467-74.

4. Jorgensen MG, Nowzari H. Aesthetic crown lengthening. Periodontol 2000. 2001;27:45-58.

5. Hulsey CM. An esthetic evaluation of lip-teeth relationships present in the smile. Am J Orthod. 1970;57:132-44.

6. Sarver DM. The importance of incisor positioning in the esthetic smile: the smile arc. Am J Orthod Dentofacial Orthop. 2001;120:98-111.

7. Dawson PE. Functional occlusion: from TMJ to smile design: Mosby; 2006.

8. Frush JP, Fisher RD. The dynesthetic interpretation of the dentogenic concept. J Prosthet Dent. 1958;8:558-81.

9. McNamara L, McNamara JA, Jr., Ackerman MB, Baccetti T. Hard- and soft-tissue contributions to the esthetics of the posed smile in growing patients seeking orthodontic treatment. Am J Orthod Dentofacial Orthop. 2008;133:491-9.

10. Tjan AH, Miller GD, The JG. Some esthetic factors in a smile. J Prosthet Dent. 1984;51:24-8.

11. Vig RG, Brundo GC. The kinetics of anterior tooth display. J Prosthet Dent. 1978;39:502-4.

12. Misch CE. Guidelines for maxillary incisal edge position-a pilot study: the key is the canine. J Prosthodont. 2008;17:130-4.

13. Gross MD, Nissan J, Ormianer Z, Dvori S, Shifman A. The effect of increasing occlusal vertical dimension on face height. Int J Prosthodont. 2002;15:353-7.

14. Hu X, Nahles S, Nelson CA, Lin Y, Nelson K. Analysis of soft tissue display during enjoyment smiling: part 1-Caucasians. Int J Periodontics Restorative Dent. 2013;33:e9-e15. 
15. Ackerman MB, Ackerman JL. Smile analysis and design in the digital era. J Clin Orthod. 2002;36:221-36.

16. Desai S, Upadhyay M, Nanda R. Dynamic smile analysis: changes with age. Am J Orthod Dentofacial Orthop. 2009;136:310 e1-10; discussion -1.

17. Chetan P, Tandon P, Singh GK, Nagar A, Prasad V, Chugh VK. Dynamics of a smile in different age groups. Angle Orthod. 2013;83:90-6.

18. Van der Geld P, Oosterveld P, Kuijpers-Jagtman AM. Age-related changes of the dental aesthetic zone at rest and during spontaneous smiling and speech. Eur J Orthod. 2008;30:366-73.

19. Schimmel M, Christou P, Houstis O, Herrmann FR, Kiliaridis S, Muller F. Distances between facial landmarks can be measured accurately with a new digital 3dimensional video system. Am J Orthod Dentofacial Orthop. 2010;137:580.

20. Ushijima M, Kamashita Y, Nishi Y, Nagaoka E. Changes in lip forms on threedimensional images with alteration of lip support and/or occlusal vertical dimension in complete denture wearers. Journal of prosthodontic research. 2012.

21. Hochman MN, Chu SJ, Tarnow DP. Maxillary anterior papilla display during smiling: a clinical study of the interdental smile line. Int J Periodontics Restorative Dent. 2012;32:375-83.

22. Crawford RW, Tredwin C, Moles D, Gill D. Smile esthetics: the influence of posterior maxillary gingival margin position. J Prosthodont. 2012;21:270-8.

23. Kattadiyil MT, Goodacre CJ, Naylor WP, Maveli TC. Esthetic smile preferences and the orientation of the maxillary occlusal plane. J Prosthet Dent. 2012;108:354-61.

24. Bidra AS, Agar JR. A classification system of patients for esthetic fixed implantsupported prostheses in the edentulous maxilla. Compend Contin Educ Dent. 2010;31:366-8

25. Bidra AS. Three-dimensional esthetic analysis in treatment planning for implantsupported fixed prosthesis in the edentulous maxilla: review of the esthetics literature. J Esthet Restor Dent. 2011;23:219-36.

26. Bidra AS, Agar JR, Parel SM. Management of patients with excessive gingival display for maxillary complete arch fixed implant-supported prostheses. J Prosthet Dent. 2012;108:324-31.

27. Atwood DA. A cephalometric study of the clinical rest position of the mandible: Part I. The variability of the clinical rest position following the removal of occlusal contacts. J Prosthet Dent. 1956;6:504-19. 
28. Prombonas A, Vlissidis D, Molyvdas P. The effect of altering the vertical dimension of occlusion on biting force. J Prosthet Dent. 1994;71:139-43.

29. Abduo J. Safety of increasing vertical dimension of occlusion: a systematic review. Quintessence Int. 2012;43:369-80.

30. Christensen J. Effect of occlusion-raising procedures on the chewing system. Dent Pract Dent Rec. 1970;20:233-8.

31. Carlsson GE, Ingervall B, Kocak G. Effect of increasing vertical dimension on the masticatory system in subjects with natural teeth. J Prosthet Dent. 1979;41:284-9.

32. Gross MD, Ormianer Z. A preliminary study on the effect of occlusal vertical dimension increase on mandibular postural rest position. Int J Prosthodont. 1994;7:216-26.

33. Ormianer Z, Gross M. A 2-year follow-up of mandibular posture following an increase in occlusal vertical dimension beyond the clinical rest position with fixed restorations. J Oral Rehabil. 1998;25:877-83.

34. Ormianer Z, Palty A. Altered vertical dimension of occlusion: a comparative retrospective pilot study of tooth- and implant-supported restorations. Int J Oral Maxillofac Implants. 2009;24:497-501.

35. Kamashita Y, Kamada Y, Kawahata N, Nagaoka E. Influence of lip support on the soft-tissue profile of complete denture wearers. J Oral Rehabil. 2006;33:102-9.

36. Mohindra NK, Bulman JS. The effect of increasing vertical dimension of occlusion on facial aesthetics. Br Dent J. 2002;192:164-8.

37. Schabel BJ, Baccetti T, Franchi L, McNamara JA. Clinical photography vs digital video clips for the assessment of smile esthetics. Angle Orthod. 2010;80:490-6.

38. Soncul M, Bamber MA. Evaluation of facial soft tissue changes with optical surface scan after surgical correction of Class III deformities. J Oral Maxillofac Surg. 2004;62:1331-40.

39. Frey DS. Bite alteration for reducing gummy smiles: Two case reports. Cosmetic Dentistry English. 2010;4:18-22.

40. Okunseri C, Pajewski NM, McGinley EL, Hoffmann RG. Racial/ethnic disparities in self-reported pediatric orthodontic visits in the United States. J Public Health Dent. 2007;67:217-23. 
Appendix A: Interview Questionnaire 
Interview Questionnaire

(This page should be destroyed at the end of session \#2)

Name:

Telephone Number:

Email Address:

Participant Number:

Scheduled Date: 
Session 1 date: Session 2 date:

Participant number:

Gender:

Age:

Ethnicity:

History of surgery in the facial area: $\mathrm{Y} / \mathrm{N}$

History of neurological disorders: $\mathrm{Y} / \mathrm{N}$

History of Orthodontics: Y / N

Allergy to Silicone: Y / N

Allergy to Nitrile: $\mathrm{Y} / \mathrm{N}$

Allergy to Alginate: $\mathrm{Y} / \mathrm{N}$

Allergies to other drugs/materials:

Inability/unwillingness to smile: $\mathrm{Y} / \mathrm{N}$

History of claustrophobia: Y / N

Persisting ear infections: $\mathrm{Y} / \mathrm{N}$

(Women only) Pregnant: Y / N

Additional information you think we should know about:

\section{To be filled out by the investigator:}

CO/CR Discrepancy >1mm: Y / N

Angle's classification: Class I Class II Class III

Anterior missing teeth: $\mathrm{Y} / \mathrm{N}$

Posterior missing teeth $>3$ in either side: $\mathrm{Y} / \mathrm{N}$

Inability to smile: $\mathrm{Y} / \mathrm{N}$

Signature of Participant

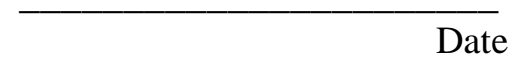

Signature of Principal Investigator

Date 